\title{
Propylene - Propane Separation using Zeolitic-Imidazolate Framework (ZIF-8) Membranes: Process Techno-Commercial Evaluation
}

\author{
Yousif Alcheikhhamdon ${ }^{1}$, Ingo Pinnau ${ }^{3}$, Bo Chen ${ }^{2}$, Mina Hoorfar ${ }^{1 *}$ \\ ${ }^{1}$ Department of Mechanical Engineering, University of British Columbia, Kelowna, Canada. \\ ${ }^{2}$ Dalian Research Institute of Petroleum \& Petrochemicals, SINOPEC, Dalian, China. \\ ${ }^{3}$ Advanced Membranes and Porous Materials Center, Division of Physical Sciences and Engineering, King Abdullah \\ University of Science and Technology, Thuwal, KSA. \\ * Corresponding author: mina.hoorfar@ubc.ca
}

\begin{abstract}
Several recent studies investigated the use of the novel Zeolitic-Imidazolate Framework (ZIF-8) membranes for olefinparaffin separation. In this manuscript, a techno-commercial model is developed to examine the use of these membranes for separating propylene from propane. Single-stage and two-stage membrane processes were assessed for their performance compared to distillation. The assessment was conducted considering $70 \mathrm{wt} \%$ propylene feed, typically produced from the upstream depropanizer. The single-stage process was found technically capable and commercially competent to produce the chemical grade propylene (93 wt\%), but not the polymer grade (99.5 wt\%). Alternatively, the two-stage process was capable of producing both propylene grades at promising recovery and cost figures. The published propylene/propane selectivity of 35 appears adequate in meeting the separation demands, subject to the adoption of proper unit design. Future research should grant more attention towards aspects such as ZIF-8 membranes' manufacturability, cost, and performance in real environments.
\end{abstract}

Keywords: ZIF-8 membrane; propylene-propane; pressure ratio; process configuration; separation cost.

Abbreviations: ZIF-8: Zeolitic-Imidazolate Framework; CMS: Carbon Molecular Sieves; XRD: X-ray Diffraction; CAPEX: Capital Expenditure; OPEX: Operating Expenditure, PR: Pressure Ratio

\section{INTRODUCTION}

Propylene is among the most important chemicals produced worldwide. The manufacturing of polypropylene, isopropyl alcohol, and propylene oxides are few examples of the propylene-based industries [1-2]. In 2015, the global production of propylene was estimated at 94.2 million tons, two-thirds of which is utilized for the production of polypropylene, the well-known thermoplastic polymer [3]. By 2025, propylene production is expected to exceed 132 million tons per year [4]. Propylene (an olefin) is offered in the market in three qualities, namely: a) refinery, b) chemical, and c) polymer grades. The purity of propylene in each grade is $35,92-95$ and $99.5-99.8 \mathrm{wt} \%$, respectively, whereas the residual is mainly propane [5].

Propylene production is mainly sourced from the steam and the catalytic cracking of paraffins (e.g. propane), accounting for 70 and $28 \%$ of the global propylene production, respectively [2,6]. Apart from the olefins, the cracking units produce by-products and unconverted feedstock [2]. The knock-off of the unconverted feedstock (e.g. propane) is essential to meet the produced propylene purity. The energy intensive distillation is the primary industrial technique adopted for separating propylene from propane. A less energy demanding technique would definitely be of industry's interest [7-8].

Several studies have investigated the use of polymeric membranes for propylene-propane separation [2,4,9-13]. However, insufficient selectivity and typically low permeability of these membranes have prevented any commercial success. Other researchers have targeted the development of non-conventional membranes, particularly the ZeoliticImidazolate Framework (ZIF-8) membranes to achieve the above-mentioned separation [14-17]. To date, ZIF-8 membranes demonstrated the most promising performance for propylene/propane separation of any known membrane material. In order to evaluate its potential for large-scale membrane-based propylene-propane separation, we investigated the technical and commercial aspects of utilizing ZIF-8 membranes in single- and two-stage process configurations. 


\section{Conventional Separation}

Distillation is the most dominant if not the only process adopted in industry to separate propylene from propane [2]. This process is energy intensive despite the tremendous efforts made by process designers to optimize it by the means of heat integration [18]. The estimates suggest that 10 to $15 \%$ of world's energy consumption is utilized in general chemical processes' distillations [19]. The propylene-propane distillation in specific, is recognized as the most energy intensive single distillation process in the US $[17,20]$.

The C3 (propylene/ propane) distillation column forms part of several distillation columns that exist in a petrochemical plant. Fig. 1 demonstrates that the separation process constitutes of two main steps: a) preliminary fractionation, and b) olefin-paraffin separation. The former refers to the process wherein the products of the cracking units are separated based on components' carbon number (C2, $\mathrm{C} 3$, etc.), i.e. irrespective of the separated cut saturation status (olefins vs. paraffins). The preliminary fractionation is relatively easier and less costly compared to the downstream olefinparaffin separation.

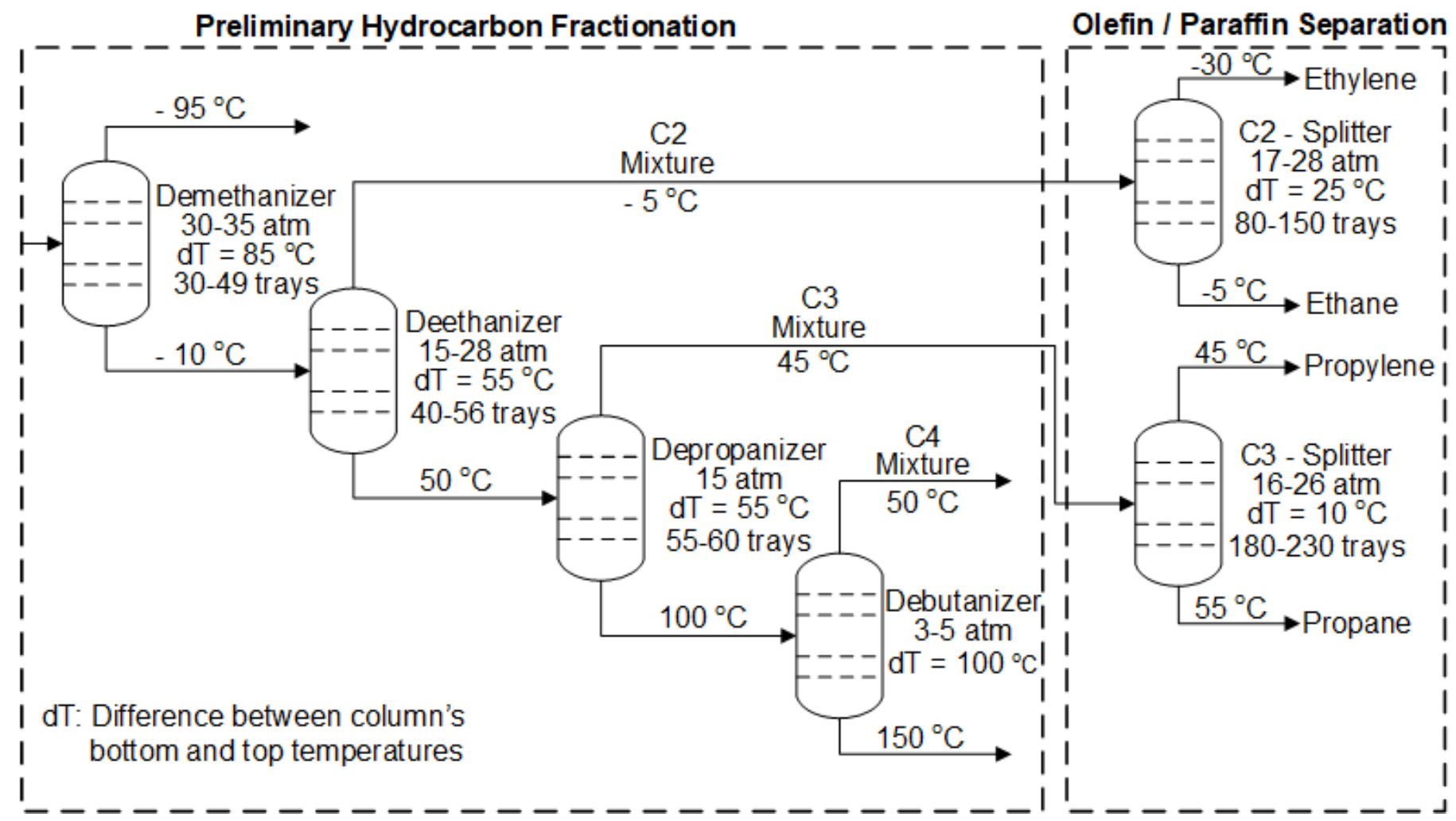

Figure 1. Separation scheme in a paraffin steam cracking plant [21].

The C3-splitters record an exceptionally high tray count due to the limited difference between propylene and propane boiling points (see Fig. 1). The height of a C3-splitter is typically between 90-100 meters, fitting around 200 trays across [22]. This exceptional height imposes several difficulties in terms of column's fabrication, construction, and logistics. To control the purity of propylene in C3 splitter's overhead, a high reflux ratio ranging between 12-20 must be maintained [15]; the column reflux system (condensers, pumps, etc.) consumes the major part of the energy consumed in the C3s distillation process. Fig. 2 demonstrates the typical flow diagram of a C3 splitter. 


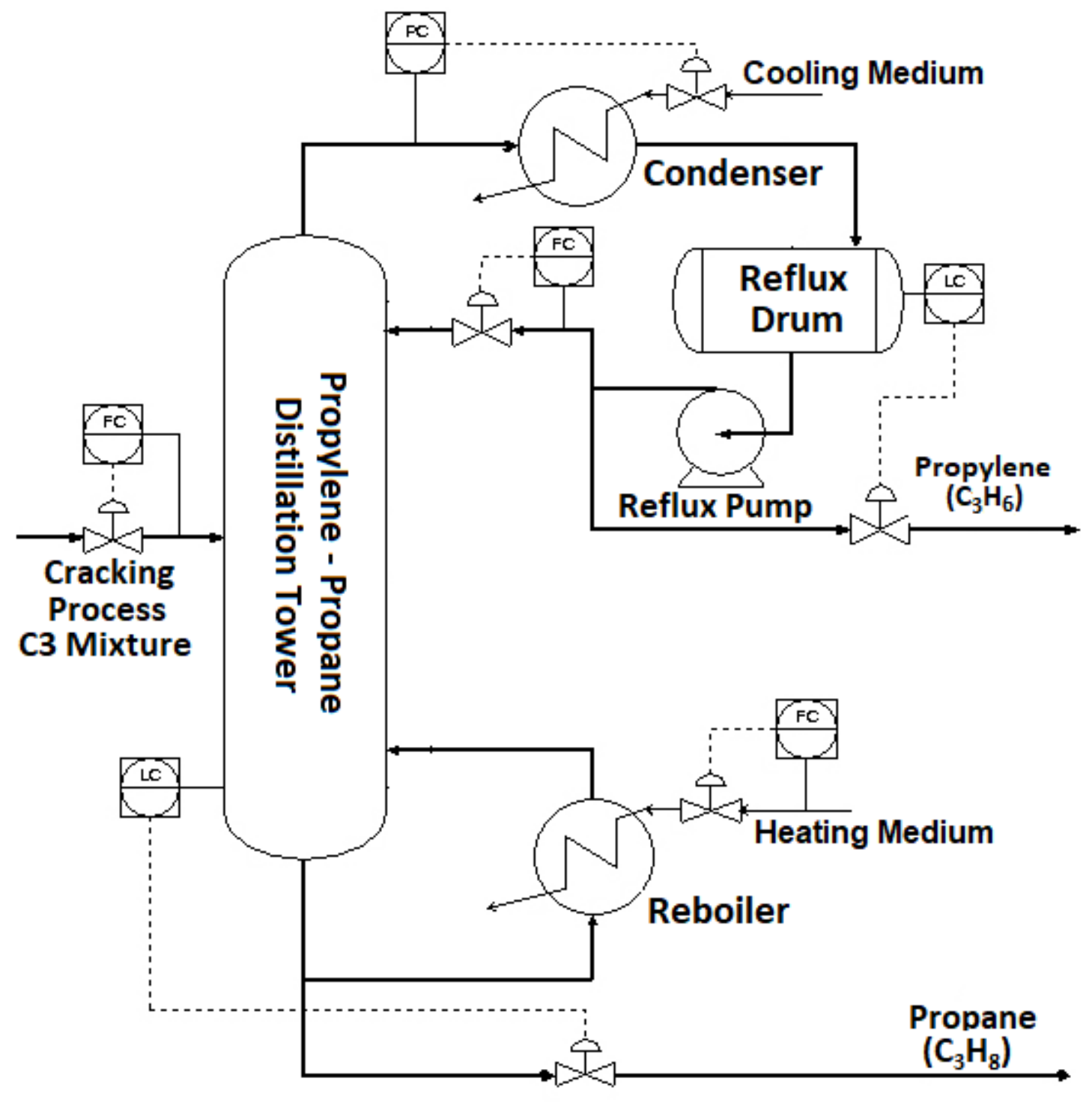

Figure 2. C3 distillation process flow diagram.

The C3 splitter is intentionally operated at high pressure as that elevates the temperature profile in the column, which in turn allows the use of low-cost cooling medium in the splitter's reflux system [5]. Furthermore, the high pressure increases the difference between propylene-propane boiling points, reducing the number of trays in the splitter. Both advantages are demonstrated in Fig. 3. It is worth highlighting that the savings associated with the above advantages overweigh the cost rise resulting from column thickness increase. 


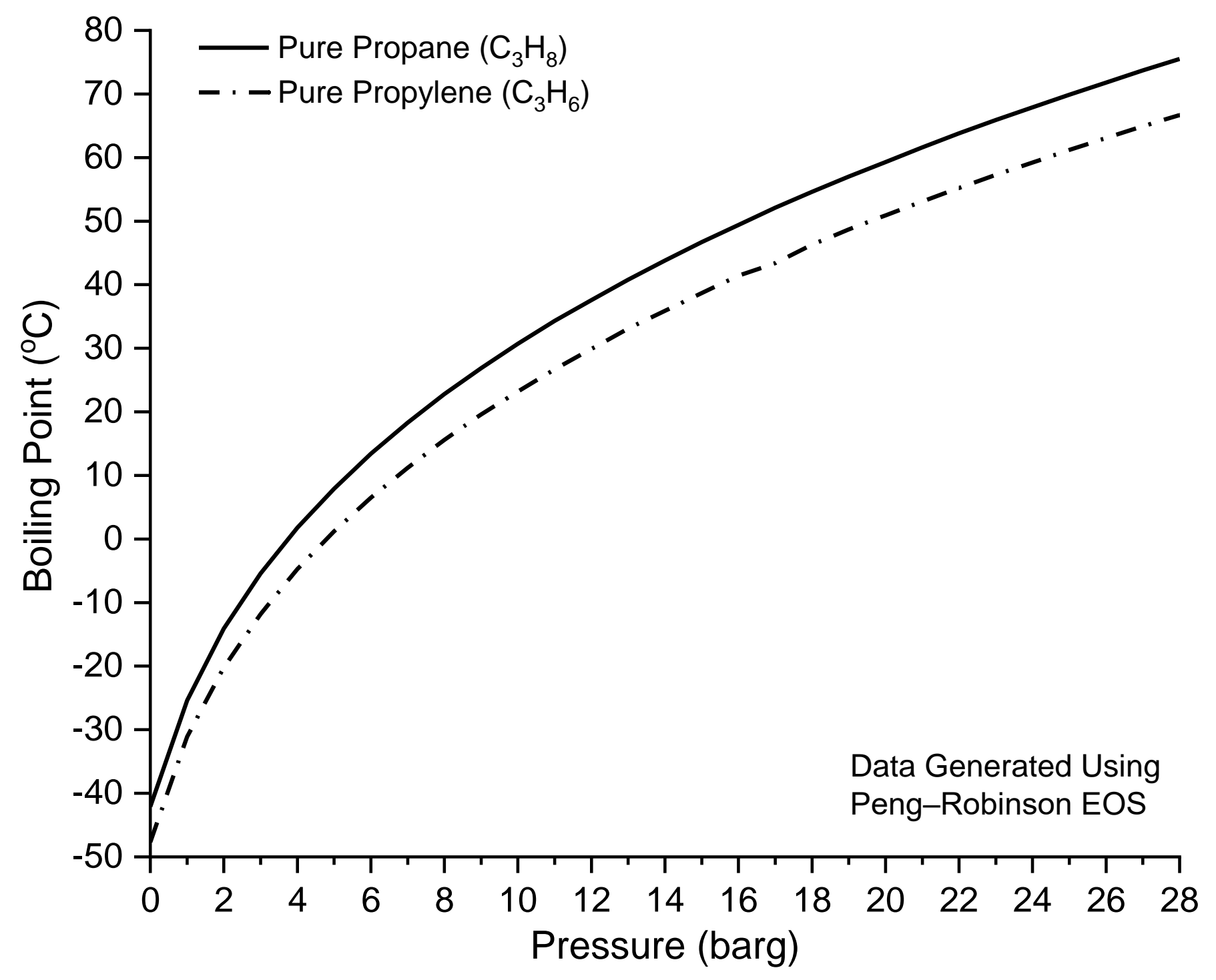

Figure 3. Propylene/propane boiling point pressure dependency.

The operating and the design parameters of C3-splitters have been significantly optimized by the extensive studies conducted in this field, and the practical experience acquired from operating numerous propylene-propane separation columns across the world.

\section{Membranes for Olefin - Paraffin Separation}

\subsection{Conventional Polymeric Membranes}

Several studies investigated the use of conventional polymeric membranes for separating propylene from propane, aiming at substituting the energy intensive distillation processes [19]. In principle, the membrane units are distinguished by their reduced energy demand, reduced footprint, and their simplified operation and troubleshooting. Their expedited construction and installation schedules offer further advantages [4]. Several membranes were developed and tested for the propylene-propane separation purpose; the tests concluded that glassy polymer membranes are much more suitable than rubbery membranes [11]. However, the performance of glassy polymer membranes is still not sufficient to substitute the well-established distillation process.

The separation performance and the durability concerns have so far prevented the adoption of membranes for separating propylene from propane on an industrial level [17]. Among the various polymeric membranes investigated 
for this purpose, glassy polyimide membranes, specifically derived from 4,4'-(Hexafluoroisopropylidene)diphthalic anhydride (6FDA), have captured the most attention [2]. The satisfactory performance of these membranes has qualified them for defining the propylene-propane separation upper bound, i.e. the best selectivity/ permeability combination among other membrane materials [2]. Koros et al. [23] defined the upper bound for propylene-propane separation membranes when operated at $35^{\circ} \mathrm{C}$, whereas Kookos described the propylene-propane selectivity / permeability trade-off by a correlation detailed elsewhere [24]. Table 1 summarises the separation properties of various 6FDA membranes under pure gas permeation tests.

Table 1. Test conditions and Pure-Gas Permeation Properties of Polyimide Membranes for Propylene/Propane [9-10,23,25]

\begin{tabular}{|c|c|c|c|c|}
\hline Polymer & $\begin{array}{c}\mathbf{p} \\
(\mathbf{a t m} .)\end{array}$ & $\begin{array}{c}\mathbf{T} \\
\left({ }^{\circ} \mathbf{C}\right)\end{array}$ & $\begin{array}{c}\text { Propylene } \\
\text { Permeability } \\
\text { (Barrer) }\end{array}$ & $\begin{array}{c}\text { Selectivity } \\
\mathbf{C}_{3} \mathbf{H}_{6} / \mathbf{C}_{3} \mathbf{H}_{\mathbf{8}}\end{array}$ \\
\hline 6FDA-mPD & 3.8 & 35 & 0.13 & 10 \\
\hline 6FDA-IPDA & 3.8 & 35 & 0.58 & 15 \\
\hline 6FDA-6FpDA & 3.8 & 35 & 0.89 & 16 \\
\hline 6FDA-DDBT & 2.0 & 50 & 1.80 & 20 \\
\hline 6FDA-TrMPD & 2.0 & 50 & 30.0 & 11 \\
\hline \multicolumn{7}{|l|}{ Matrimid® } & 2.0 & 35 & 0.10 & 10 \\
\hline 1 Barrer $=10^{-10} \mathrm{~cm}^{3}$ (STP) $\cdot \mathrm{cm} / \mathrm{cm}^{2} \cdot \mathrm{sec} \cdot \mathrm{cmHg}$ \\
\hline
\end{tabular}

The propylene/propane selectivity of polymer membranes is dependent on the diffusivity $(D)$ and the solubility $(S)$ of propylene gas compared to propane (see Eq. 1).

$$
\alpha_{\mathrm{C} 3 \mathrm{H} 6 / \mathrm{C} 3 \mathrm{H} 8}=\left(\mathrm{D}_{\mathrm{C} 3 \mathrm{H} 6} / \mathrm{D}_{\mathrm{C} 3 \mathrm{H} 8}\right) \times\left(\mathrm{S}_{\mathrm{C} 3 \mathrm{H} 6} / \mathrm{S}_{\mathrm{C} 3 \mathrm{H} 8}\right) \quad(\text { Eq. } 1)
$$

Both diffusivity and solubility ratios contribute positively towards higher propylene selectivity. However, the selectivity is mainly dominated by the diffusivity ratio governed by the kinetic diameters difference. The solubility ratio is slightly above unity in polyimide membranes [9-10].

Most of the membrane performance data quoted in literature including these in Table 1 and upper bound data are based on pure-gas permeation tests [9]. When the same membranes are tested under mixed gas (more realistic) conditions, up to $50 \%$ drop in membrane selectivity was noted [2,9]. This drop is ascribed to the competitive sorption phenomena described elsewhere [26-27]. Thus, marketing membrane technology for propylene/propane separation while quoting the selectivity figures from pure-gas tests can be misleading. Similarly, performing techno-commercial studies based on the pure-gas test data would result in biased outcomes. A previous study suggested that a minimum membrane selectivity of 35 is required to substitute the conventional distillation units with a two-stage membrane process for producing polymer grade propylene [28-29]. Up to date, none of the commercial polyimide membranes have satisfied the indicated selectivity figure in a mixed-gas environment [17]. This caused some researches to suggest the use of membranes in a hybrid system (membrane plus distillation) for minimizing the distillation load [24,30]. Matsukata et al. [31] demonstrated that remarkable energy saving can be achieved when a membrane unit of reasonable separation properties is coupled with a distillation column to form a hybrid process.

Bickel et al. [9] observed that the selectivity of a polyimide membrane can be prone to severe deterioration due to plasticization (swelling of the membrane matrix); this occurs when the concentration of propylene or propane in membrane's material exceeds a certain threshold [12]. Pressure increase propagates membrane plasticization in view of the increased C3s concentration in the membrane polymeric structure. The reported permeation tests in literature were mostly conducted at low pressures (1-2 atm), since remarkable performance deterioration were noted at high pressures [2]. Several researchers attempted to suppress plasticization in 6FDA-based polymers [11-12]. Polymer cross-linking and post-treatment dense film annealing (thermal treatment) were proven effective in increasing the resistance of membranes against plasticization. Koros et. al [11] demonstrated that 6FDA-6FpDA membrane can resist plasticisation up to $5 \mathrm{~atm}$ (pure gas test) when subjected to film annealing treatment; however, no data is available for the performance of such membranes above $5 \mathrm{~atm}$.

\subsection{Zeolitic-Imidazolate Framework (ZIF-8)}

The shortages associated with polymeric membranes performance have led researchers to the development of nonconventional membranes for propylene-propane separation. Facilitated transport membranes [32-37] and carbon 
molecular sieves membranes (CMS) [30,38-43] are examples of these developments. Despite their satisfactory separation performance, facilitated transport membranes were not commercialized due to their unsustainable performance; these membranes are prone to irreversible performance loss upon the poisoning of their selective silver ion carriers [44]. Similarly, carbon molecular sieves (CMS) membranes did not find their way to commercialization yet. Because of their brittle mechanical properties, CMS membranes are difficult to scale up [45]. Furthermore, the CMS membranes are prone to performance loss upon their exposure to oxygen or air, making their handling and preservation a challenging process [46]. Recent attempts targeted at the development of alternative membrane materials and transport mechanisms. Kanezashi et al. [16,47-48] demonstrated promising results when testing Aldoped organosilica and fluorine-induced microporous silica membranes for propylene-propane separation. The associated separation properties were found comparable to these of ZIF-8 membranes. The Al-doped organosilica and fluorine-induced microporous silica membranes are not the main focus of this paper.

Several researches investigated the use of Zeolitic-Imidazolate Frameworks (ZIFs) to enhance the performance of polymeric membranes for propylene-propane separation [14-15,49]. ZIF is a novel class of ordered porous crystalline materials, which can be utilized to prepare membranes with properties similar to these containing zeolites, i.e. membranes with uniform/precise pore size and high thermal/chemical stabilities. The ZIFs constitute of tetrahedrally coordinated transition metal ions ( $\mathrm{Zn}(\mathrm{II})$, Co(II), etc.) which are connected by imidazolate linkers. Among the various ZIFs presented in literature, most attention was granted to the ZIF-8, which is composed of zinc atoms with 2-methyl imidazole moieties as ligands.

The suitability of ZIF-8 for propylene-propane separation is directly linked to its distinguished ZIF-8 crystal size, which allows the rejection of propane while permeating propylene. By X-ray diffraction (XRD), the ZIF-8 crystal aperture is determined to be $3.4 \AA$ [50]. The flexible framework of the ZIF-8 crystal allows the permeation of gases having molecular diameters up to $4.2 \AA$, implying the permeation of propylene $(4.0 \AA)$ at higher rates compared to propane $(4.3 \AA)$ [50-51]. The ZIF-8 membrane synthesis techniques and the impact of those on membranes' performance are described elsewhere [52-53]. The presence of ZIF-8 in a membrane enhances its separation selectivity, noting that the diffusivity of propylene across a ZIF-8 crystal has been estimated to be 100 times more than that of propane [54]. This figure forms the ideal and thus the maximum selectivity possible for a ZIF-8 based-membrane.

Lai et al. [15] fabricated and tested ZIF-8 membranes using an equimolar propylene-propane mixture. To illustrate the results reproducibility, five membrane sets were prepared and tested under identical conditions. Similarly, Kwon et al. [14] prepared and tested three similar membranes; the results were consistent. Tsapatsis et al. [49] has recently developed and tested ZIF-8 membranes with an equimolar feed; the tests conducted at high pressure ratios concluded performance values comparable to that of other studies. In fact, Tsapatsis et al. [49] demonstrated outstanding selectivity values, ranging from 50 to 70 at specific testing conditions. The results of all three studies are summarized in Table 2.

Table 2. Experimental Separation Properties of ZIF-8 Membranes at Room Temperature.

\begin{tabular}{|l|c|c|c|c|c|}
\hline \multicolumn{1}{|c|}{ Developer } & Propylene Permeance(GPU) & Selectivity $\left(\mathrm{C}_{3} \mathrm{H}_{6} / \mathbf{C}_{3} \mathrm{H}_{8}\right)$ & $\mathbf{T}\left({ }^{\circ} \mathbf{C}\right)$ & Feed $\mathbf{p}(\mathbf{a t m})$ & Ref \\
\hline Lai et al. & $83.0 \pm 19.0$ & $34.6 \pm 6.4$ & $\sim 22$ & 1 & {$[15]$} \\
\hline Kwon et al. & $79.8 \pm 2.7$ & $38 \pm 1.1$ & Room T & 1 & {$[14]$} \\
\hline Tsapatsis et al. & $85-100$ & 45 & Room T & Up to 7 & {$[49]$} \\
\hline $1 \mathrm{GPU}=10^{-6} \mathrm{~cm}^{3}(\mathrm{STP}) \mathrm{cm}^{-2} \mathrm{~s}^{-1} \mathrm{~cm} \mathrm{Hg}^{-1}$ & \multicolumn{5}{l}{} \\
\hline
\end{tabular}

Table 2 demonstrates that the performance results are consistent and reproducible. Furthermore, the minimum selectivity threshold (i.e., 35) quoted in previous studies as a prerequisite for conventional distillation replacement is satisfied [28]. In a recent work by Pan et al. [55], the selectivity was boosted to around 100, i.e. close to that of a pure ZIF-8 crystal. The applied silicone rubber (PDMS) coating was effective in blocking the defects, and also in hindering the ZIF-8 framework flexibility. The coated membranes demonstrated sustainable performance at high feed to permeate differential pressures (6 atm) [55]. In fact, the interfacial defects caused by the filler (e.g. ZIF-8) / polymeric membrane incompatibility is the major limitation that hinders the industrial implementation of Mixed Matrix Membranes (MMMs). In a recent work [56], excellent compatibility was observed between the ZIF-8 filler and the 6FDA polymeric matrix, when the latter is being functionalized with hydroxyl groups; loading capacities as high as $65 \%$ were recorded [56]. 
All the selectivity values listed in Table 2 were recorded at room temperature. Some studies have been conducted to investigate the effect of temperature variations on the performance of ZIF-8 membranes. The experiments performed by Lai et al. [15] and Hara et al. [17] both demonstrated that the increase of temperature would result in a drop in ZIF8 membrane's selectivity. The tests performed by Lai et al. [15] demonstrated that between 0 to $60{ }^{\circ} \mathrm{C}, \sim 5 \%$ drop in selectivity was experienced for each $10^{\circ} \mathrm{C}$ increase in operating temperature. The latter implies that operating the membrane unit at lower temperature would be more effective. However, the increase of processing cost as the result of feed gas cooling (e.g. refrigeration) must be noted.

The ZIF-8 membranes have been found thermally stable, evidenced by the repeatability of the results when subject to temperature cycles [15]. As for the impact of the propane/propylene mixture, Lai et al. [15] demonstrated that the selectivity of ZIF-8 membranes was enhanced (up to 40) as the feed gas composition approached pure propylene, and it decreased (down to 25) as the composition approached pure propane. The opposite was demonstrated in the supplementary material of [49] upon operating the permeate side under vacuum. All tests were conducted at room temperature.

No studies have so far investigated the effect of contaminants presence on the performance of ZIF-8 membranes. Furthermore, the potential for ZIF-8 membrane plasticization upon its operation at high feed gas pressure (e.g. 15 atm) has not been not sufficiently investigated. Apart from the performance aspect, limited studies [49] were conducted for analyzing the technical or the commercial feasibility of manufacturing ZIF-8 membranes on an industrial scale. All the indicated research offsets offer future research opportunities.

To promote the research related to ZIF-8 membranes, it is crucial to first demonstrate the commercial competency of ZIF-8 membrane units compared to distillation, which is the scope of this work. Advantageous or comparable costs promote ZIF-8 related membranes research, specifically for propylene/propane separation.

\section{SimUlation \& Costing OF SEPARATION Processes}

The conventional propylene-propane distillation process has been well established. For this process a few decades of operation resulted in extensive optimization, enabling the purification of propylene to the desired grade (chemical or polymer) at an optimized cost [18]. Given that the distillation process meets the targeted purification, the alternative processes (e.g. ZIF-8 membranes-based processes) cannot be solely promoted on the basis of achieving the targeted purification. Factors such as the separation cost, unit footprint, capacity advantages, reliability and operational flexibility must also be addressed. The cost competency forms one of the end-users most appealing factors. For the separation cost estimation, the performance of the distillation and membrane processes must be first predicted; the latter can be best achieved following process simulations.

\subsection{Process Schemes}

Process scheme definition is a critical step while designing membrane-based separation processes. Despite its importance, less attention is often granted to the "membrane process design" subject when compared to other aspects of the technology e.g. "membrane materials development".

Most of the literature related to the customization of multi-stage membrane processes pertains to the natural gas purification processes [57]. The customization is dependent on various factors including, but not limited to, process objective, operating conditions, and membrane selectivity. Unlike to the natural gas purification processes where the end-product (natural gas) is retrieved from the membrane's high-pressure side, the propylene-propane separation process end-product (propylene) is retrieved from the membrane's low-pressure side. The alteration of the product retrieval pressure explains the non-applicability of the natural gas purification process design for the propylenepropane separation application. In this work, the three configurations illustrated in Fig. $\mathbf{4}$ and $\mathbf{5}$ were analyzed. The complexity of the configurations involving more than two stages causes them to be excluded from this study given their infrequent use.

The absence of recycle compressors in the design of the single-stage process (see Fig. 4) reduces the unit footprint, process complexity, and unit's capital cost. However, the latter indicated advantages occur at the cost of low propylene recovery, particularly when membranes of limited propylene selectivity are utilized. 


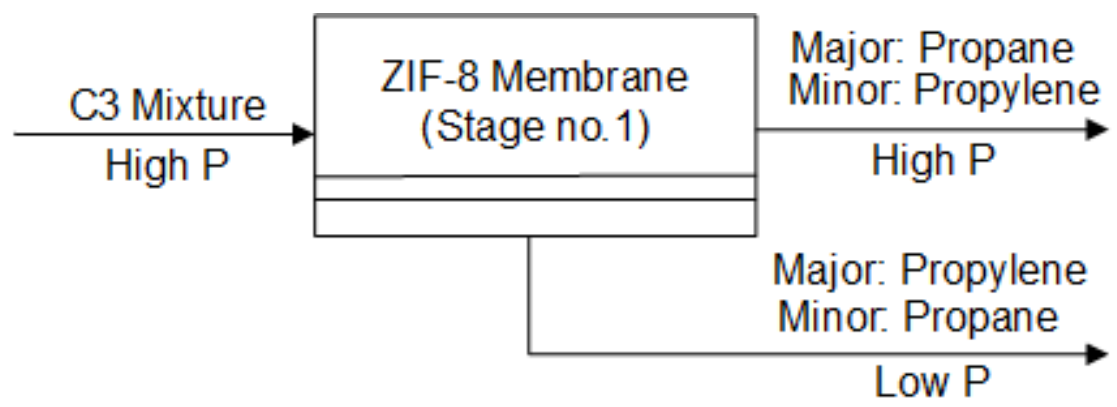

Figure 4. Single-stage process for propylene-propane separation.

The two-stage configurations (see Fig. 5) offer better propylene recovery. However, at the cost of increased capital investment and process complexity. 


\section{Process Configuration $2 \mathrm{~A}$}

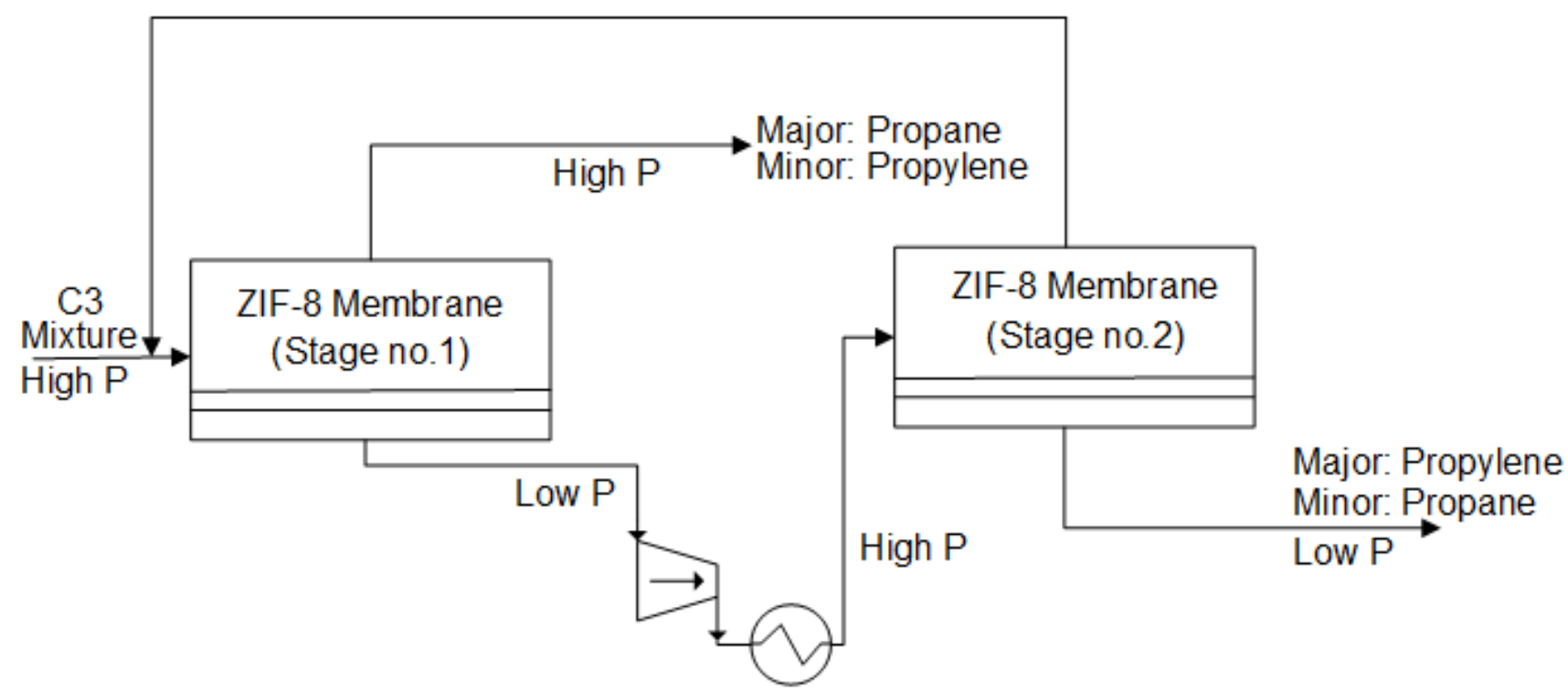

\section{Process Configuration 2B}

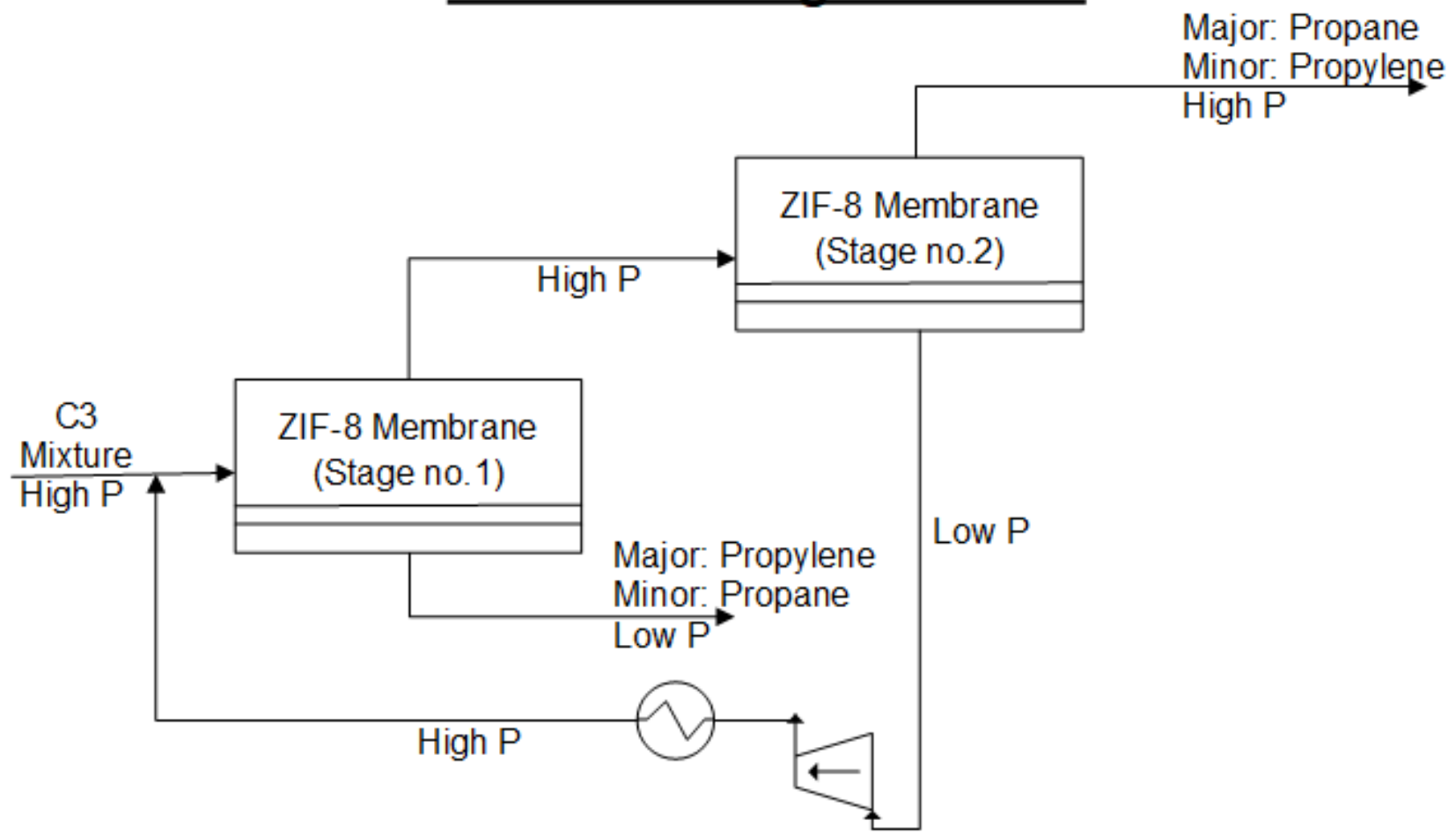

Figure 5. Two-stage propylene-propane separation based on the concentration of the permeate pas (2A) or the residual pas (2B).

The differences between these two sub-configurations $(2 \mathrm{~A} / 2 \mathrm{~B})$ are summarized in Table 3. When the targeted separation can be met using any of these sub-configurations, the selection of the process scheme selection will be mainly governed by the process economics, i.e. the lower separation cost. 
Table 3. Summary of Two-stage Configurations for Propylene-Propane Separation.

\begin{tabular}{|c|c|c|c|c|c|}
\hline$\#$ & Separation Principle & $\begin{array}{c}\text { Propylene Purity } \\
\text { Control via }\end{array}$ & $\begin{array}{c}\text { Propylene Recovery } \\
\text { Control via }\end{array}$ & $\begin{array}{c}\text { Propylene } \\
\text { Recovery Point }\end{array}$ & $\begin{array}{c}\text { Recycle Stream } \\
\text { Source }\end{array}$ \\
\hline 2A & $\begin{array}{c}\text { Permeate } \\
\text { Gas Concentration }\end{array}$ & Membrane Stage 2 & Membrane Stage 1 & Stage 2 Permeate & Stage 2 Residual \\
\hline 2B & $\begin{array}{c}\text { Residual } \\
\text { Gas Concentration }\end{array}$ & Membrane Stage 1 & Membrane Stage 2 & Stage 1 Permeate & Stage 2 Permeate \\
\hline
\end{tabular}

In this work, the single and the two-stage configurations were simulated, costed, and compared with the conventional distillation cost as explained later in Sections 4.2 and 4.3.

\subsection{Simulation Methodology}

The process schemes elaborated in Section 3.1 are modelled as part of this research work. The presence of the recycle stream in the two-stage designs complicates the components' mass balance solutions, noting that tedious iterations are required for the convergence of associated calculations. For such modeling, the use of a process simulator is crucial since a) it eases the convergence, and b) it facilitates the intended optimization. None of the common process simulators (e.g. Aspen HYSYS, ProMax®, etc.) offer "membranes" among their standard "process functions". Our research group has recently developed the HYSYS extension "MemCal", which supports the simulation of solution-diffusion based membranes in the Aspen HYSYS simulation environment. From the developed extension user interface (see Fig. 6), the membrane stage key design parameters can be manipulated. The details related to "MemCal" and its development are elaborated elsewhere [58].

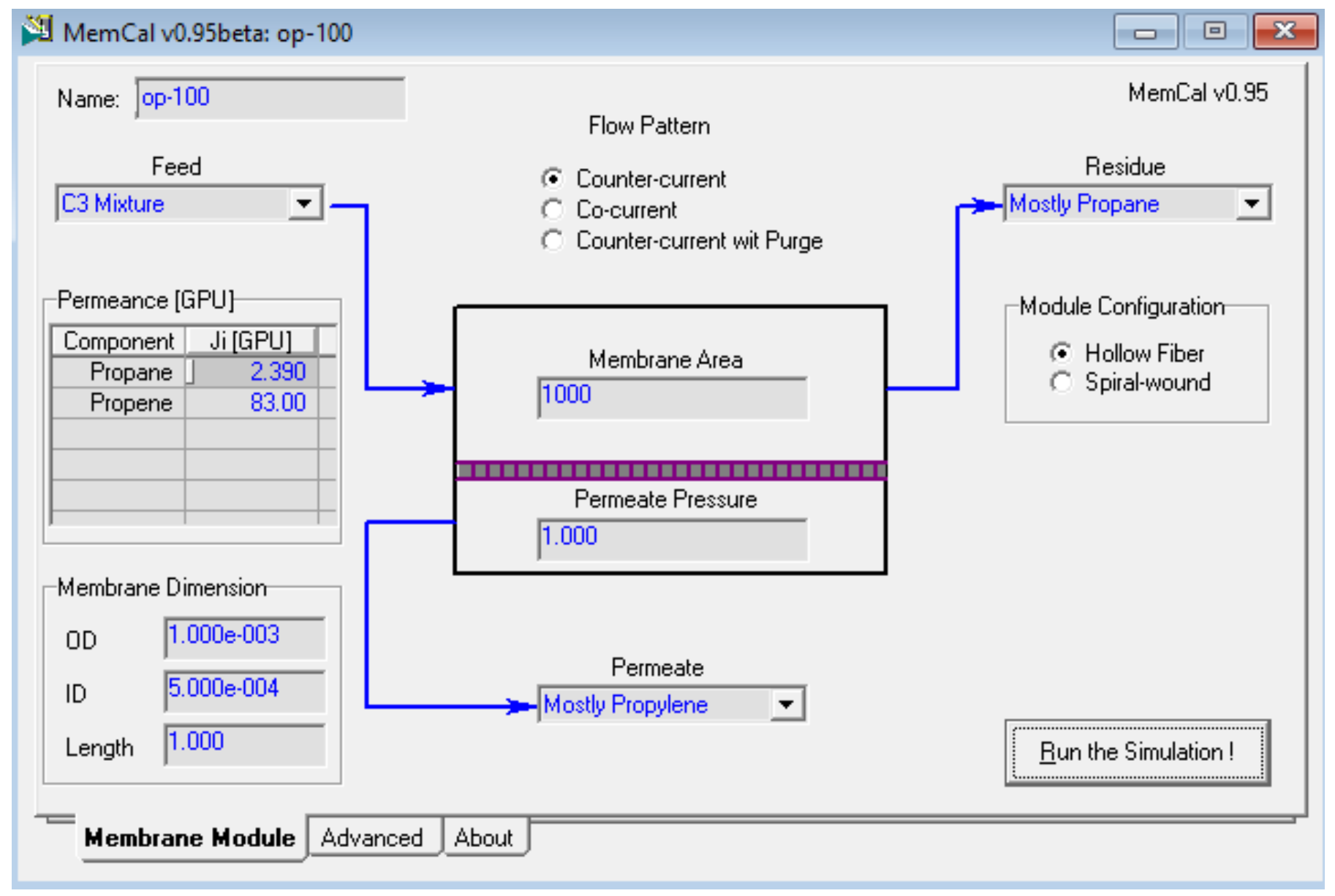

Figure 6. HYSYS Extension "MemCal” User Interface. 
While simulating the two-stage (2A/2B) configurations, the default HYSYS process functions (e.g. mixers, recycle blocks, compressors, coolers, etc.) are used to complete the process modelling. The fluid package "Peng-Robinson" was utilized for all conducted simulation.

This study was aimed at comparing the techno-commercial aspects of membrane units against those of conventional distillation. The modeling of the distillation tower is less complex than that of the membrane unit, noting that the refluxed distillation tower is among the Aspen HYSYS readily available operations. Two specifications must be defined by the user to converge the propylene-propane distillation column. The first is the propylene concentration in the column overhead, since this forms the distillation process objective. The second is selected to be the column's reflux ratio, noting its influence in defining column performance and economics. The simulator maps the performance of the column by conducting iterative heat and mass such that the two defined specifications are met [59-60].

\subsection{Costing Methodology \& Envelope}

The cost prediction exercises assist researchers in setting technology targets. However, the prediction of separation cost is a challenging exercise in view of the numerous inputs that must be tabulated into the costing models. In this research work, a costing model was established for the single- and two-stage configurations. Also, a simplified costing model was established for the propylene-propane distillation process. The costing models were intentionally established within the simulation environment for easy import of the costing data from the process simulator. Furthermore, the establishment of the costing model within the simulation environment allows the use of simulator's in-built optimizer while optimizing (minimizing) the separation cost. For all the modelled processes (including distillation), the propylene-propane separation cost constitutes of capital expenditure (CAPEX), operational expenditure (OPEX), and propylene loss cost [61]. The cost described in this context is limited to the separation operations conducted downstream of the depropoanizer (see Fig. 1). Thus, the difference between the separation cost and the propylene market value does not reflect the profitability of the propylene production process. For the latter to be calculated, all the costs associated with the conversion of paraffins to olefins as well as the cost of the preliminary fractionation must be considered in the calculation. However, this is not the scope of this manuscript. The separation cost is expressed in US\$ cents per kilogram of the produced propylene.

It must be highlighted that the thermal distillation process yields a readily liquefied product, qualifying the produced propylene for direct storage and transportation. The liquefaction is a by-product of column's reflux establishment, which is critical for propylene purity control. Oppositely, the membrane process yields gaseous propylene in accordance with the membrane process operating phase. This research work will not consider the cost of propylene gas liquefaction post the membrane process, since the work focuses on accomplishing the propylene purity irrespective of its phase. In fact, the preference towards the produced propylene phase (gaseous or liquid) is highly dependent on the industry or the application planned downstream of the purification unit.

\subsubsection{Costing of Membrane-based Processes}

The membrane process cost is distributed between the unit's CAPEX, OPEX and product loss. The CAPEX mainly accounts for the membrane, the recycle compressor, the interconnecting piping, and the instrumentation costs. As for the OPEX, it mainly accounts for the costs associated with the membranes' periodic replacements, the recycle compressor power, the labor, and the unit maintenance. The propylene loss caused by the imperfect membrane selectivity is a main cost contributor, particularly when no recovery stages are involved. The value of the propylene dissipated during the separation is treated as an "opportunity loss", i.e. a loss of a potential revenue.

Table 4 illustrates the data used for simulating and costing the membrane units. The performance data quoted in the Tsapatsis et al. [49] ZIF-8 membranes tests demonstrated slightly higher propylene permeability and selectivity compared to the other tests [14-15], see Table 3. However, the simulations in this manuscript are performed based on the Lai et al. [15] data for conservative analyses. Lai et al. [15] performance data is assumed to stand valid for a feed pressure of $7 \mathrm{~atm}$, noting the promising results recorded by Tsapatsis et al. [49] at $7 \mathrm{~atm}$ feed pressure.

Table 4. Membrane Units' Design and Costing Data.

\begin{tabular}{|l|c|c|}
\hline \multicolumn{1}{|c|}{ Parameter } & Value & Unit \\
\hline Location & Onshore (Unrestricted) & - \\
\hline Unit Feed Flow & 20 & ton/h \\
\hline Propylene in Feed & $\begin{array}{c}\text { Single-stage: } 5-90 \\
\text { Two-stage: } 70\end{array}$ & wt\% \\
\hline
\end{tabular}




\begin{tabular}{|c|c|c|}
\hline Parameter & Value & Unit \\
\hline Feed Pressure & 7 & atm \\
\hline Permeate Pressure & 1 & atm \\
\hline Pressure Ratio $(P R)$ & 7 & - \\
\hline Feed Temperature & 35 & $\stackrel{\circ}{-} \mathrm{C}$ \\
\hline Flow Mode & Counter-current, no permeate purge & - \\
\hline Membrane & ZIF-8 & - \\
\hline Propylene $\left(\mathrm{C}_{3} \mathrm{H}_{6}\right)$ Permeance & 83.0 & GPU \\
\hline Propane $\left(\mathrm{C}_{3} \mathrm{H}_{8}\right)$ Permeance & 2.4 & GPU \\
\hline Membrane Selectivity & 34.6 & - \\
\hline Targeted Propylene Purity & $\begin{array}{l}\text { 93.0\% (Chemical Grade), } \\
\text { 99.5\% (Polymer Grade) }\end{array}$ & $w t \%$ \\
\hline Membrane Lifetime & 4 & Years \\
\hline Unit Lifetime & 12 & Years \\
\hline Unit Availability & 95 & $\%$ \\
\hline ZIF-8 Membrane Cost & $100-500$ & $\mathrm{US} \$ / \mathrm{m}^{2}$ \\
\hline Investment Interest Rate & 5 & $\%$ \\
\hline Labor Cost & 40 & US\$/hr \\
\hline $\begin{array}{l}\text { Polymer Grade Propylene } \\
\text { Price }\end{array}$ & $0.785(1.73)$ & US\$/lb $(\$ / k g)$ \\
\hline
\end{tabular}

The performed costing covers attempts to produce both chemical grade (93 wt\%) and high-quality polymer grade $(99.5 \mathrm{wt} \%)$ propylene if feasible. The membrane stages areas are manipulated such that the targeted propylene purity is met at the least separation cost. Among the various possible flow modes (parallel flow, cross-flow, countercurrent), the membrane units with the counter-current flow mode are intentionally simulated, as this mode offers the maximum permeation potential and thus the least membrane area requirement. The latter maximizes the advantage of the membrane units compared to distillation.

The cost of a ZIF-8 membrane is assumed to be in the range of $100-500 \mathrm{US} \$ / \mathrm{m}^{2}$, which is comparable to the cost range considered by Tsapatsis et al. [49] in a recent relevant work. The lower limit of the above range, $100 \mathrm{US} \$ / \mathrm{m}^{2}$, represents the cost of a typical polymeric membrane [4] to denote a membrane with minimum ZIF-8 loading. As for the upper limit, $500 \mathrm{US} \$ / \mathrm{m}^{2}$ is the figure considered for a polymeric membrane with $50 \% \mathrm{ZIF}-8$ loading. Drioli et al. [45] expected that a zeolite membrane would cost around $1000 \$ / \mathrm{m}^{2}$ once produced on a large-scale. Though the filler material is different, the above figure is stated in this context for an indicative purpose.

Because the feed is assumed to be comprised of propane and propylene only, no membrane pre-treatment units are considered. Furthermore, the costing assumes no sparing provided within the units (e.g. no recycle compressor spare); the latter influences the units CAPEX. As for the product loss contribution, the propylene dissipated in the unit's residual gas is valued at $1.73 \$ / \mathrm{kg}$, which is the market price for the almost pure polymer grade propylene. The same cost functions used by Hao et al. [61-63] were used for estimating the separation cost.

The separation cost in single- and two-stage (2A/2B) configurations were calculated at the targeted propylene quality and the assumed membrane costs. The resultant costs were evaluated against that of the thermal distillation process.

\subsubsection{Costing of Thermal Distillation Processes}

The breakdown of the thermal distillation process costs is similar to that of the membrane units, i.e. CAPEX, OPEX and product loss. The CAPEX mainly accounts for the distillation tower, column internals, reflux system, reboiler, and instrumentation costs. As for the OPEX, it is mainly dominated by the refrigeration power consumed in the column's reflux system, and the duty consumed in the column's reboiler. The dissipation of propylene in the column's bottom stream is also a cost contributing factor.

Table 5 illustrates the basis for the thermal distillation process simulation and costing. The pressure range selected for operating the thermal distillation tower is $16-26 \mathrm{~atm}$, which is the range recommended in literature for optimum tower operation [21]. In terms of the tower's dimensions, the diameter of the tray tower is dependent on the column vapor traffic, whereas its height is defined by the tray count and the inter-tray spacing ( $2 \mathrm{ft} /$ tray). The column reflux ratio adopted in the simulations is within the range (12-20) specified in the literature for optimum tower operation [15]. 
Table 5. Thermal Distillation Design and Costing Data

\begin{tabular}{|c|c|c|}
\hline Parameter & Value & Unit \\
\hline Location & Onshore (Unrestricted) & - \\
\hline Unit Feed Flow & 20 & ton $/ \mathrm{h}$ \\
\hline Propylene in Feed & 70 & $w t \%$ \\
\hline Feed Pressure & 15 & atm \\
\hline Feed Temperature & Saturated Liquid & $\stackrel{\circ}{\circ}$ \\
\hline Column Reflux Ratio & $17-21$ & - \\
\hline Column Pressure Drop & 1 & atm \\
\hline Column Stages Count & $190-250$ & - \\
\hline Column Tray Type / Material & Valve / CS & - \\
\hline Tray Efficiency & $85 \%$ & \\
\hline Reflux Cooling Medium / Cost & Chilled Water at 0.354 & US\$/GJ \\
\hline Propylene Product Phase & $3^{\circ} \mathrm{C}$ Sub-cooled Liquid & - \\
\hline Reboiler Heating Medium / Cost & LP Steam at 14.05 & US\$/GJ \\
\hline Heat Integration (reboiler) & 50 & $\%$ \\
\hline Electrical Power Cost & 0.06 & US $\$ / \mathrm{kWh}$ \\
\hline Labor Cost & 40 & US $\$ / \mathrm{hr}$ \\
\hline Equipment Cost Index Year & 2018 & - \\
\hline Unit Lifetime & 12 & Years \\
\hline Unit Availability & 95 & $\%$ \\
\hline Targeted Propylene Purity & 99.5\% (Polymer Grade) & wt\% \\
\hline Polymer Grade Propylene Price & 1.73 & US\$/kg \\
\hline
\end{tabular}

\section{ReSULTS AND Discussion}

This section demonstrates the outcomes of the simulation and the costing performed for the a) single-stage ZIF-8 membrane-based process, b) multi-stage ZIF-8 membrane-based process, and c) thermal distillation process. The objective of assessing these processes was to explore the potentials of ZIF-8 membrane units in replacing the thermal distillation process, considering both the technical and the commercial aspects.

\section{1 $\quad$ Single-stage Process}

The membrane process separation fundamentals are best presented in single-stage designs (see Fig. 4), where the process scheme is its simplest form. The failure of a membrane to achieve a separation could be explained by: a) membrane performance shortage (e.g. low selectivity), b) process conditions limitation (e.g. low pressure ratio), or c) combination of both. Typically, most attention in the literature is directed towards membrane performance enhancement, since the process conditions do not often limit separation processes. In the most common gas separation applications (e.g. natural gas treatment), the gas is fed to the membrane at high pressures, which guarantees sufficient pressure ratio $(P R)$ across the membrane, and thus an adequate gas permeation potential. This is not the case in the ZIF-8 membrane-based propylene/propane separation processes, where the pressure ratio across the membrane could limit unit's performance. The indicated limitation adds up to the performance shortage caused by the limited selectivity of ZIF-8 membranes. Huang et al. [64] demonstrated that for a solution-diffusion based membrane, and assuming the utilization of a non-limiting membrane (e.g. infinite selectivity), the maximum concentration of a component in the permeate stream cannot be boosted from the component feed concentration by a factor exceeding the pressure ratio (see Eq. 2 and 3). Hence, positive permeation potential (the partial pressure difference) must be maintained across the entire membrane area in order to sustain propylene's permeation.

Enrichment Limit $=\frac{\text { Propylene } \% \text { in permeate }}{\text { Propylene } \% \text { in feed }}<\frac{P(\text { feed })}{P(\text { Permeate })}$ (Eq. 2$)$

Or upon its rearrangement,

Max Propylene $\%$ in Permeate $=$ Propylene $\%$ in feed $x$ Pressure Ratio (Eq. 3)

Based on Eq. 3, if a pressure ratio $(P R)$ of 7 was imposed across a perfect membrane, it would not be possible to produce chemical (93 wt\%) and polymer (99.5 wt\%) grade propylene unless the concentrations of propylene in the 
feed exceed 13.3 and 14.2 wt\%, respectively. If the feed concentration drops below the latter indicated figure, the process becomes "pressure ratio limited", i.e., irrespective of the utilized membrane selectivity, the targeted purities would not be feasible.

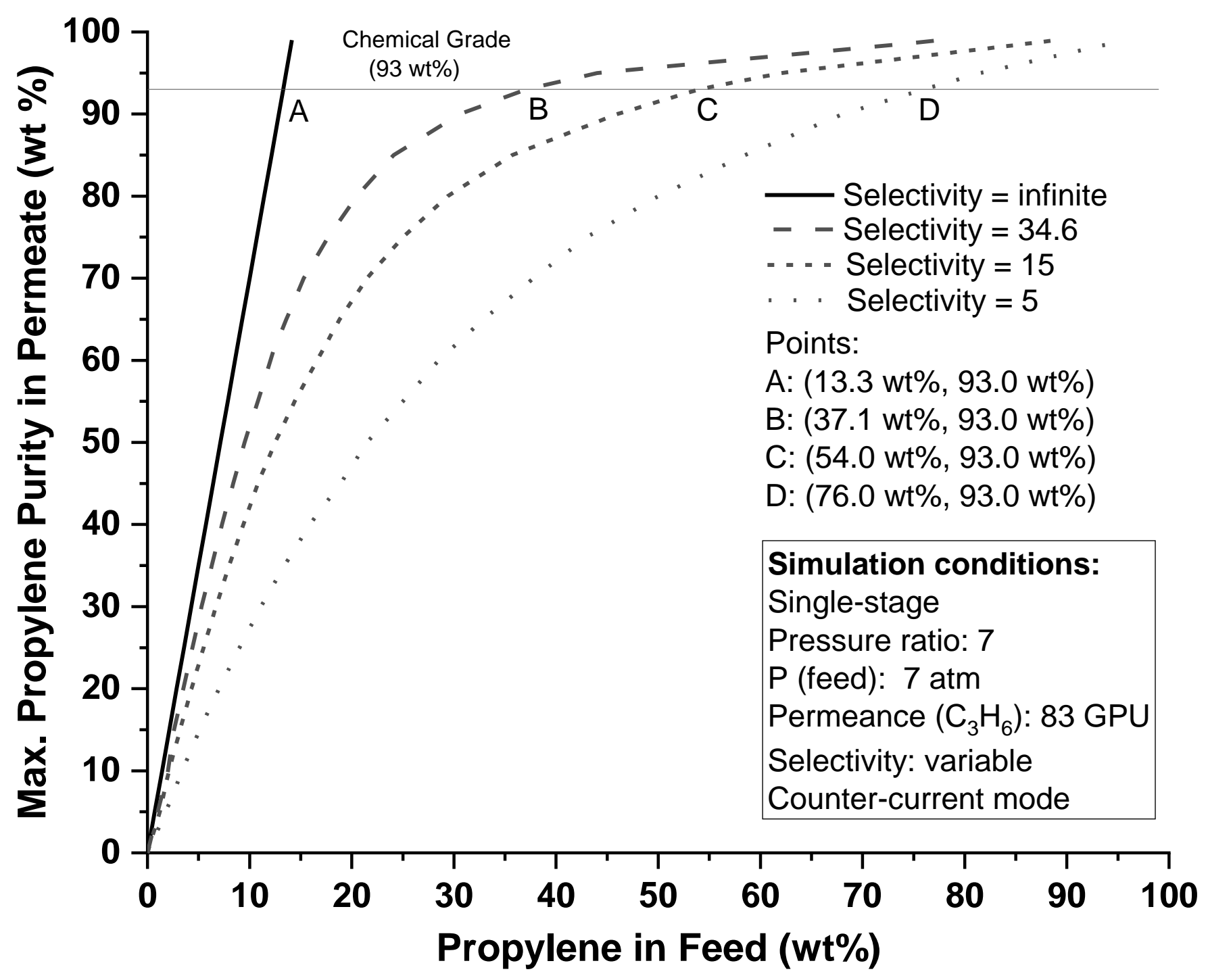

Figure 7. Single-stage design - maximum propylene purity vs. feed concentration at various membrane selectivities

In fact, the concentration of propylene in the unit feed must be higher than these indicated figures due to the following:

a) The concentration of propylene drops as the high-pressure gas approaches the membrane's unit discharge. This drop could cause the adopted pressure ratio being inadequate for producing the targeted propylene purity from the last high-pressure membrane segments. The described drawback leads to the low recovery of propylene at the targeted purity.

b) The minimum feed concentration (e.g. 13.3 wt\% to produce the chemical grade) is calculated based on the assumption of utilizing a perfect propylene selective membrane. Upon the utilization of imperfect membranes (e.g. ZIF-8), the propylene in the feed must be present at higher concentrations to compensate the membrane's performance offset (see points A-D in Fig. 7).

The ability of a process to achieve the targeted propylene purity does not necessarily imply its economic competency; propylene recovery is a crucial design factor that must be analyzed during process assessment. Fig. $\mathbf{8}$ demonstrates 
the relation between propylene's recovery and feed composition in the attempt of producing chemical or polymer grade propylene at different pressure ratios using a single-stage ZIF-8 membrane process. "Propylene recovery" is defined as the ratio of the propylene present in the on-spec. process product stream (permeate) to the propylene present in the process feed stream.

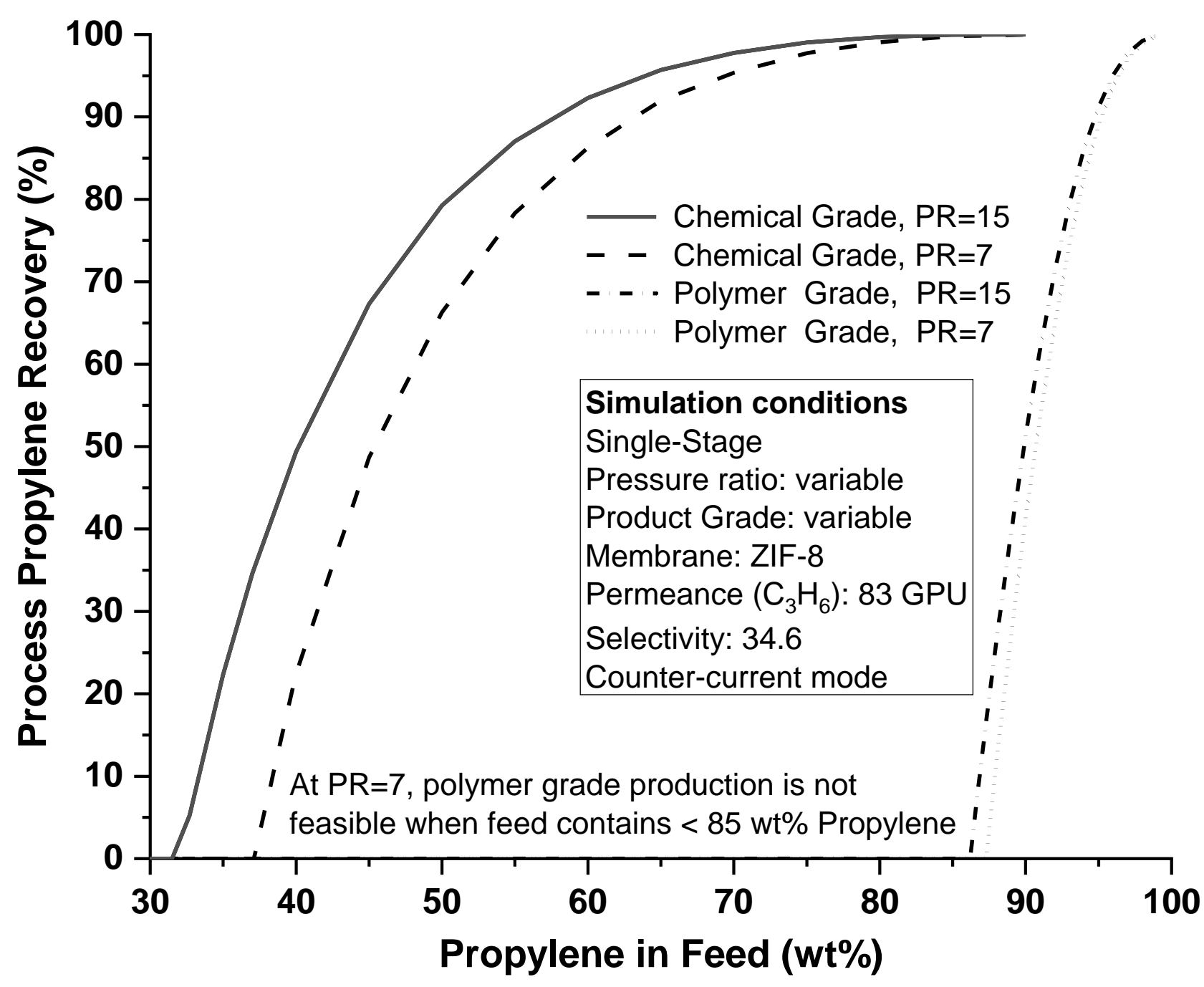

Figure 8. Single-stage design - maximum possible propylene recovery vs. feed concentration at the produced grade and the operating pressure ratio.

a) The production of chemical grade propylene from a $70 \mathrm{wt} \%$ feed (catalytic cracking unit product) is possible, with recovery of $\sim 95 \%$. The residual propylene is dissipated along with the unit's residual gas. The separation cost and its breakdown are summarized in Table 6.

b) The production of polymer grade propylene from a $70 \mathrm{wt} \%$ feed (catalytic cracking unit product) is not possible at any of the imposed pressure ratios. The production of polymer grade propylene from a single-stage ZIF-8 membrane system is associated with impractical feed compositions.

c) The use of a single-stage ZIF-8 membrane unit for upgrading propylene from the chemical grade to the polymer grade is possible. However, the recovery figures are not impressive (75-80\%).

d) The application of higher $P R$ enhances the recovery at all feed concentrations. However, the enhancement becomes less significant as the concentration of propylene in the unit's feed increases. The performance of ZIF-8 membranes at $P R$ of 15 has not been verified experimentally. Nevertheless, the simulations were conducted at this $P R$ for demonstrating the effect of $P R$ manipulation on the unit's overall performance. It is worth highlighting that the 
C3 mixture is often available off the depropanizer overhead at $15 \mathrm{~atm}$ [21], forming a free-of-charge permeation potential for the downstream membrane unit.

In a single-stage process, the recovery ratio is highly dependent on the utilized membrane selectivity. The latter is boosted when the percentage increase in fast gas (propylene) permeance exceeds that of the slow gas (propane). If the permeance of both gases experience equal improvements (e.g., by $10 \%$ ), no effects will be seen on membrane's selectivity and subsequently the unit's recovery ratio. The advantage will be limited to the reduction of the membrane area required for separation. The trade-off between propylene's purity and recovery in single-stage processes operating with membranes of various selectivities is demonstrated in Fig. $\mathbf{9 .}$

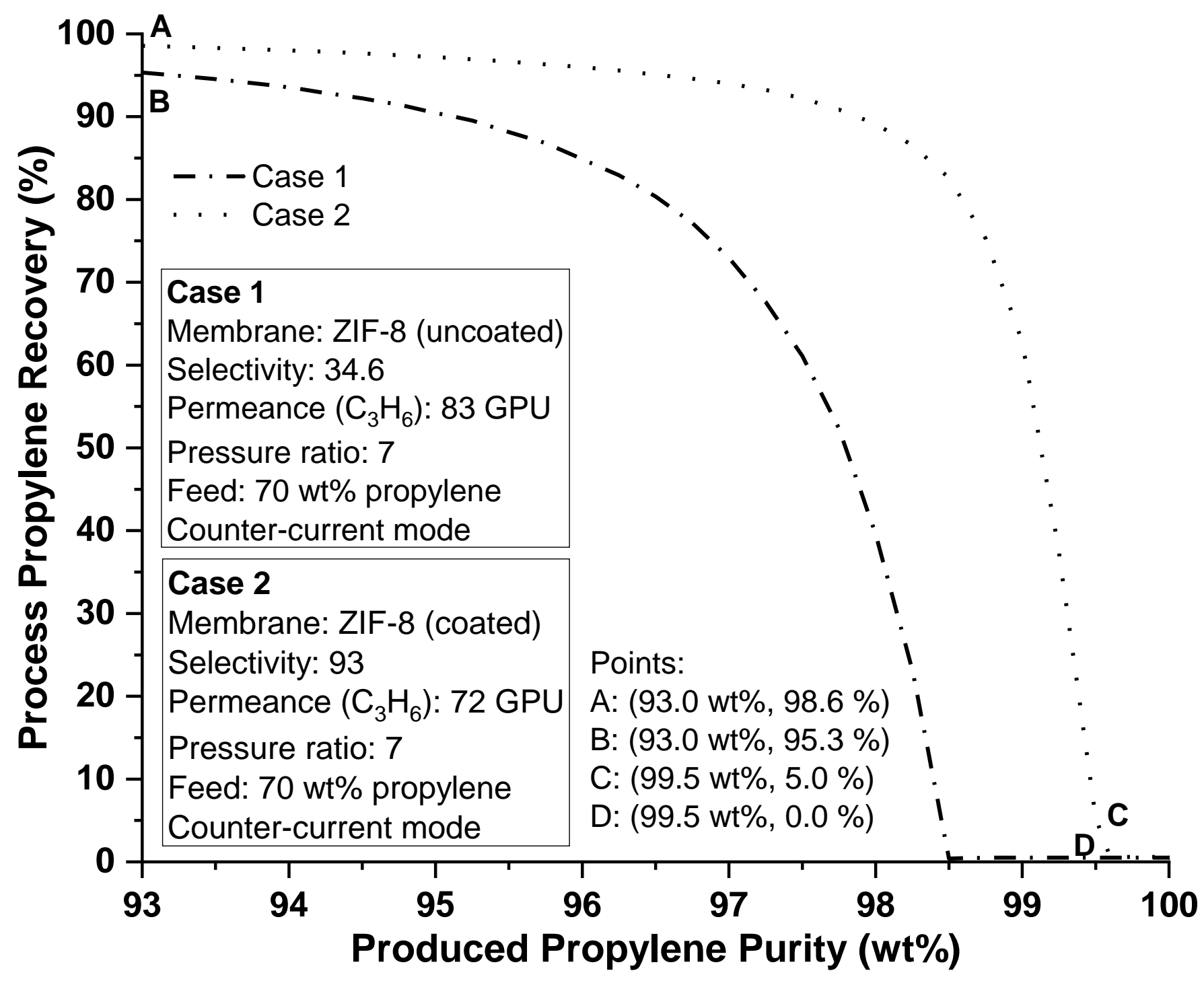

Figure 9. Single-Stage Design - Propylene's Recovery and Purity Trade-off at Various Selectivities

In spite of their enhanced selectivity, the ZIF-8 membranes coated with rubbery PDMS ( $\alpha=93$ ) [55] are still incapable of producing the polymer grade propylene from $70 \mathrm{wt} \%$ propylene feed mixtures; the resultant recovery is poor (see points $\mathrm{C}$ in Fig. 9). As for the chemical grade production, the adoption of the coated membrane results in a minor recovery boost when compared to the uncoated membranes (see points A-B in Fig. 9).

In summary, the single-stage ZIF-8 membrane-based system is qualified to produce the chemical grade propylene at reasonable propylene recovery values (above 95\%). The enhancement of selectivity (above 35) does not improve the unit's recovery significantly. On the other hand, the single-stage process is far from producing the polymer grade even if the membrane selectivity approaches that of a pure ZIF-8 crystal $(\alpha=100)$. At operating conditions identical to those 
described in Fig. 9, a minimum selectivity value of 485 is required to achieve $90 \%$ propylene recovery while meeting the polymer grade purity (99.5 wt\%); such selectivity figures are not feasible with ZIF-8 based membranes.

\subsection{Two-Stage Process}

The two-stage designs aim at overcoming the single-stage process shortfalls. Obviously, the two-stage system will be capable of producing the chemical grade, given the ability of the single-stage process to do so. If a two-stage process is adopted for the chemical grade production, the cost associated with the additional membrane stage (along with compression) must be weighed against the benefits demonstrated by the additional recovery. The second stage might not be economically justified, especially if the membrane is expensive (e.g. $500 \$ / \mathrm{m}^{2}$ ). The details related to the production of the chemical grade using a two-stage membrane system are summarized later in Table 6.

The two-stage analyses in the following sections will focus on the production of the polymer grade, which the singlestage process fails to produce. The two-stage designs involve a recovery (recycle) system which limits the amount of propylene dissipated in the unit's residual gas. In this study, the two-stage analyses operate with a $70 \mathrm{wt} \%$ feed; the previous relevant studies $[4,49]$ adopted similar composition on the basis that the depropanizer following the catalytic cracking unit produces this gas mixture. A two-stage compression unit was considered to limit the pressure ratio across the recycle compressor.

\subsubsection{Process Scheme Selection}

This section studies the better performing two-stage configuration (2A vs. $2 \mathrm{~B}$, see Fig. 5 ) by comparing their process propylene recovery at various recycle ratios. Both configurations are simulated assuming the production of the polymer grade propylene (99.5 wt\%) from a $70 \mathrm{wt} \%$ propylene feed, see Fig. 10.

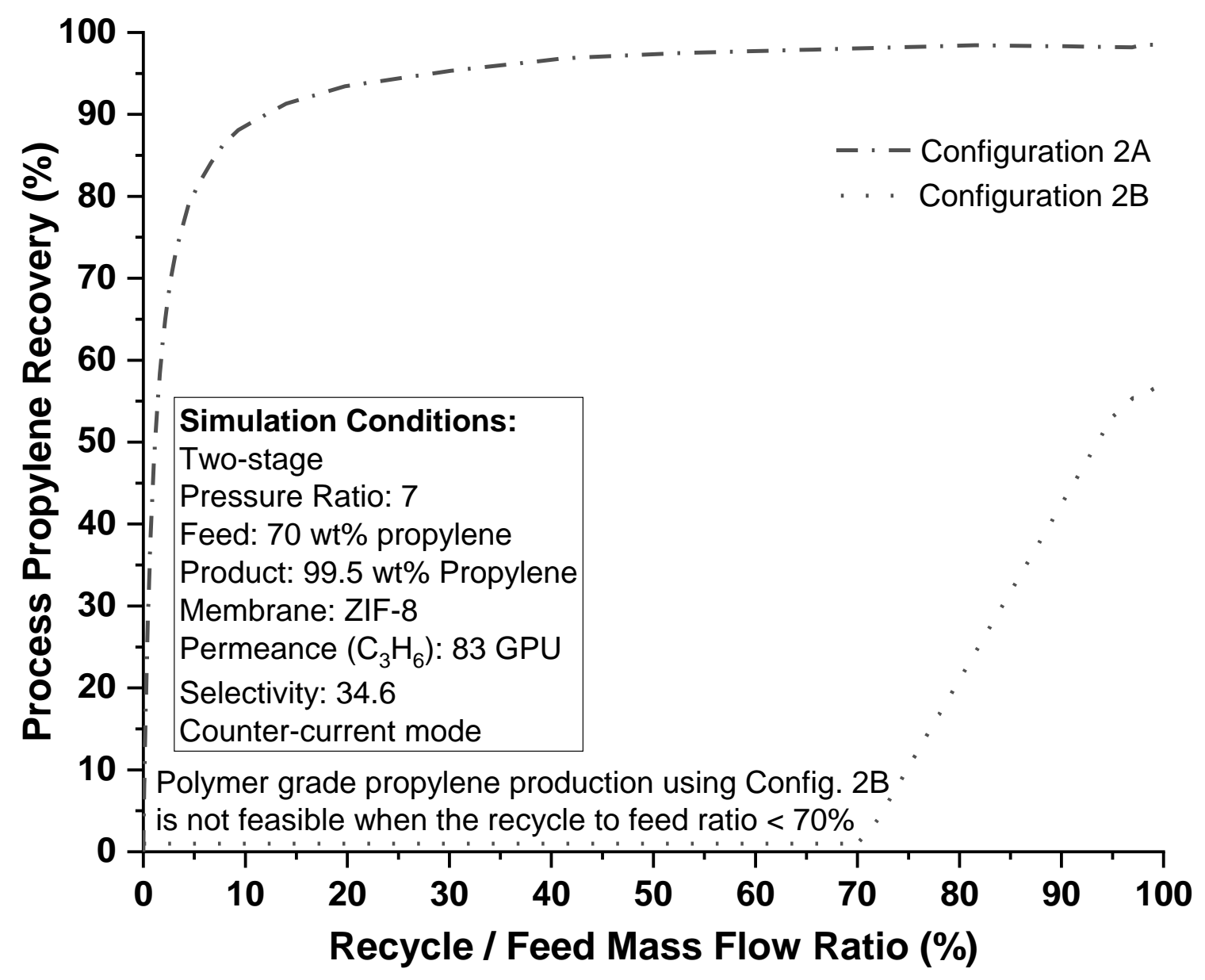

Figure 10. Two-stage unit propylene recovery vs. recycle ratio. 
Configuration $2 \mathrm{~A}$ which adopts the principle of permeate gas concentration demonstrated higher recovery and thus better performance than configuration $2 \mathrm{~B}$ at all recycle ratios. The increase of recycle ratio is proven advantageous in boosting the unit's propylene recovery. However, the rate of the increase experiences a slowdown as the recycle ratio increases. Thus, the recycle ratio must be optimized such that the revenues gained from the boost of propylene's recovery overweigh the costs associated with recycle ratio increase. These costs pertain to the extra compression capacity and the growth in membrane area demand. The latter is particularly important when utilizing expensive membranes, see Section 4.2.2.

\subsubsection{Polymer Grade Propylene Production}

The analyses in this section will only detail the Configuration 2A, in view of 2B's incompetency (see Section 4.2.1). Using a two-stage ZIF-8 membrane system, the production of polymer grade propylene (99.5 wt\%) from a $70 \mathrm{wt} \%$ propylene feed is possible. Beside the technical feasibility, the separation cost must also be examined. The modeling / costing is performed as per Table 4. In Fig. 11, propylene recovery and separation cost are expressed as functions of the recycle ratio. The modeling assumes that each membrane stage operates at $P R$ of 7 , which is the highest $P R$ at which the performance of ZIF-8 membranes was verified experimentally [49].

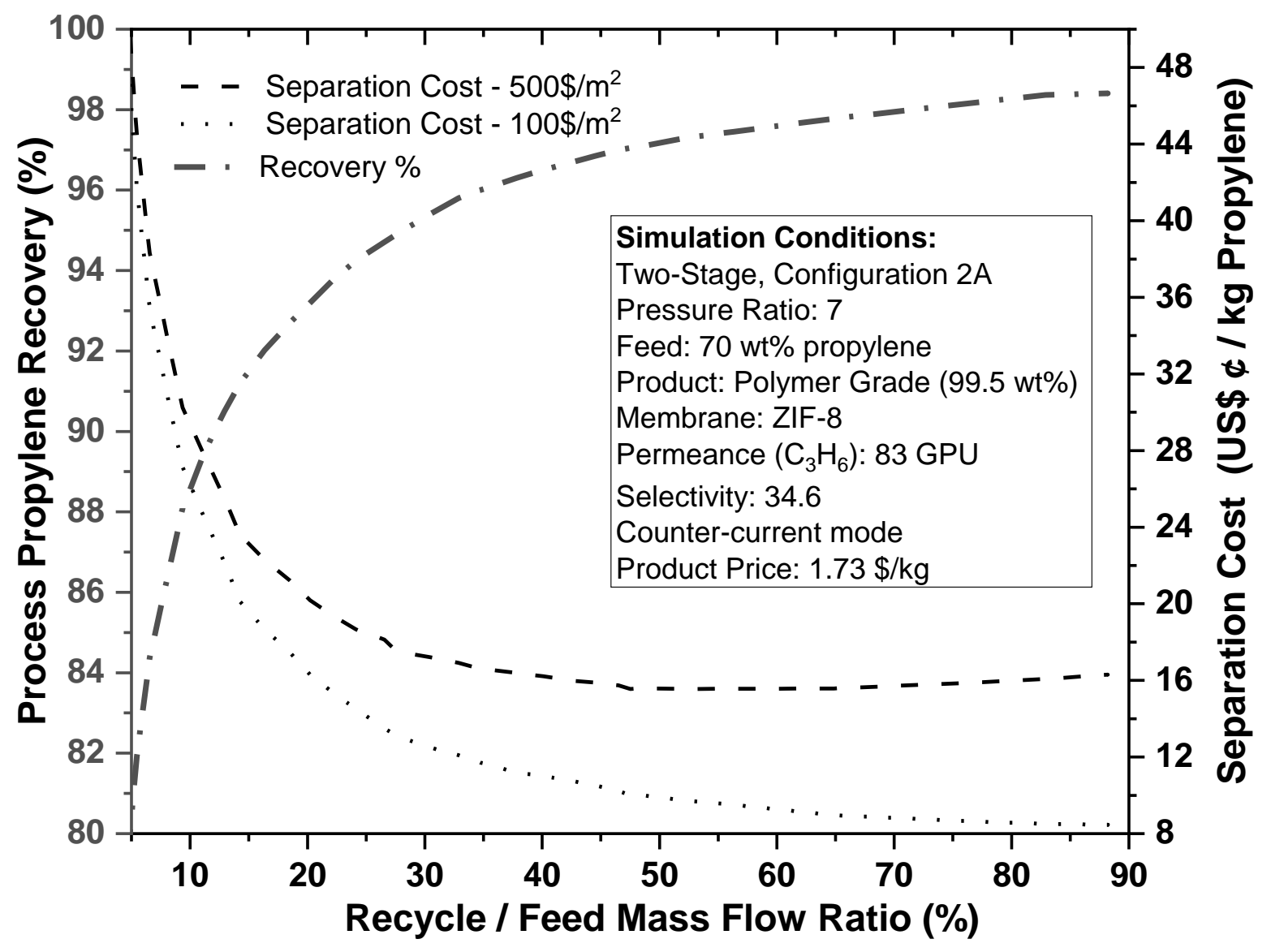

Figure 11. Recovery rates and separation costs vs. recycle ratios (configuration $2 A, P R=7$ )

Fig. 11 shows that the increase of the recycle ratio is correlated with an improvement in the unit's propylene recovery. However, the rate of increase slows down at high recycle ratios. For instance, no significant improvement in propylene recovery is noted at recycle ratios $>50 \%$. At a recycle ratio of $46 \%$, configuration $2 \mathrm{~A}$ recorded a propylene recovery of $97 \%$, which corresponds to separation costs between 10.2 and 15.8 US cents per $\mathrm{kg}$ of polymer grade propylene, depending on the membrane price. The separation cost breakdown is summarized in Table 6. Economically, the separation process is not justified if the purification cost exceeds the final product (propylene) market value (173 US cents $/ \mathrm{kg}$ ). In this context, the ratio of the separation cost to the propylene market value is used as an indication for evaluating the economic competency of a process. Clearly, a separation process is regarded more cost-effective if the described ratio is low. The separation cost of configuration $2 A$ forms no more than $\sim 6-9 \%$ of the polymer grade propylene market value, implying that the separation process is economically justified. 
The performance of a ZIF-8 membrane at 15 atm feed (the upstream depropanizer pressure) has not been verified in the published literature. However, to demonstrate the positive advantage of pressure ratio increase on the unit's performance, the two-stage simulation results are reproduced at $P R$ of 15, see Fig. 12.

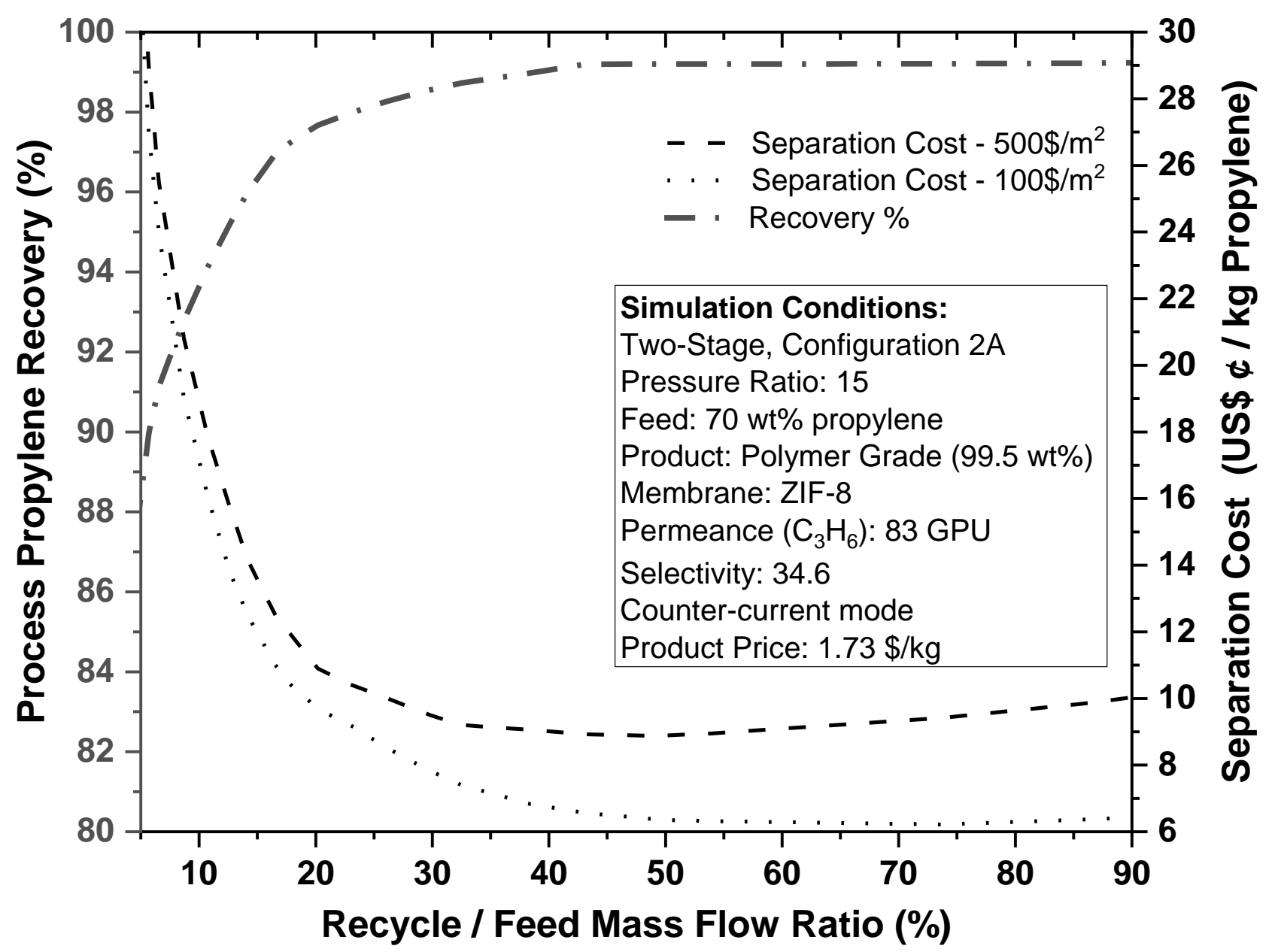

Figure 12. Recovery rates and separation costs vs. recycle ratios (configuration $2 A, P R=15$ )

The results in Fig. 12 suggest that operating the membrane unit at high pressure ratio reduces the recycle ratio required to achieve a certain recovery. For example, operating the membrane at $P R$ of 15 reduces the recycle to feed ratio required to achieve $97 \%$ recovery from $46 \%$ (at $P R=7$ ) to $18 \%$; the latter is advantageous in reducing the membrane unit's footprint. Furthermore, the pressure ratio increase reduces the membrane area required for separation, and thus reduces the unit's capital investment; this advantage is more obvious when the utilized membranes are expensive (e.g. $500 \$ / \mathrm{m}^{2}$ ). The separation cost at membrane price of $500 \$ / \mathrm{m}^{2}$ is estimated at 12.5 US cents per $\mathrm{kg}$ of polymer grade propylene, which is $22 \%$ less than the separation cost at $P R$ of 7 .

In terms of the energy consumption, the simulations suggest that a two-stage membrane unit consumes $70-80 \%$ less energy than the thermal units. In a two-stage membrane unit, the energy consumption is highly dependent on the feed pressure, which in-turn dictates the number of required compressor stages, their associated compression ratios, and the energy consumed in the compressors' after-coolers. The reduced energy demand reflects positively on the environment. As for the footprint, it is envisaged that a two-stage membrane unit would result in a much more compacted design compared to a thermal unit; the latter is known for its numerous equipment. The estimation of footprint saving is pending the development of membrane modules, based on which the ratio of separation area to volume (and hence footprint) can be estimated. 
Irrespective of the applied $P R$, the two-stage ZIF-8 membrane system (2A) seems qualified to produce the polymer grade propylene at competent cost. However, it is crucial to investigate the feasibility and the cost associated with the production of ZIF-8 membranes on an industrial scale. Other aspects such as product handling, logistics, and preservation must also be assessed. All the latter investigations form opportunities for future research.

\subsection{Thermal Distillation Process}

The thermal distillation process (C3-splitter) costing considers the same feed (70 wt\%) and product (99.5 wt\%) specs as used for the two-stage membrane processes. The C3-splitter is simulated at 15 atm, which is the typical operating pressure of the upstream depropanizer. Column's reflux ratio and tray count are preliminary optimized within the ranges specified in Table 5 to minimize the separation cost. Increasing the reflux ratio enhances the column's overhead purity and results in a reduced tray count. However, the latter occurs at the cost of extra duty in the column's reboiler and condenser. To some extent, the reflux ratio in the distillation process is analogous to the recycle ratio in the two-stage membrane processes. In the analyses, it is assumed that $50 \%$ of the reboiler's required heat is achieved by heat integration. Design parameters other than those considered in this work can still be part of the optimization process [65]. However, this is outside the scope of this paper which grants more focus to the membrane processes.

The analyses suggest that the separation cost in a distillation unit is not much lower than that of a two-stage membrane unit; the cost is mainly dominated by the operating expenditure dictated by column's heating and cooling operations. The distillation operations result in satisfactory recovery $(>99.5 \%)$, making the contribution of the propylene loss to the total separation cost insignificant. The separation cost and its breakdown are summarised in Table 6.

Table 6. Summary of Simulation Results: Single-stage, Two-Stage, and Thermal Distillation Processes

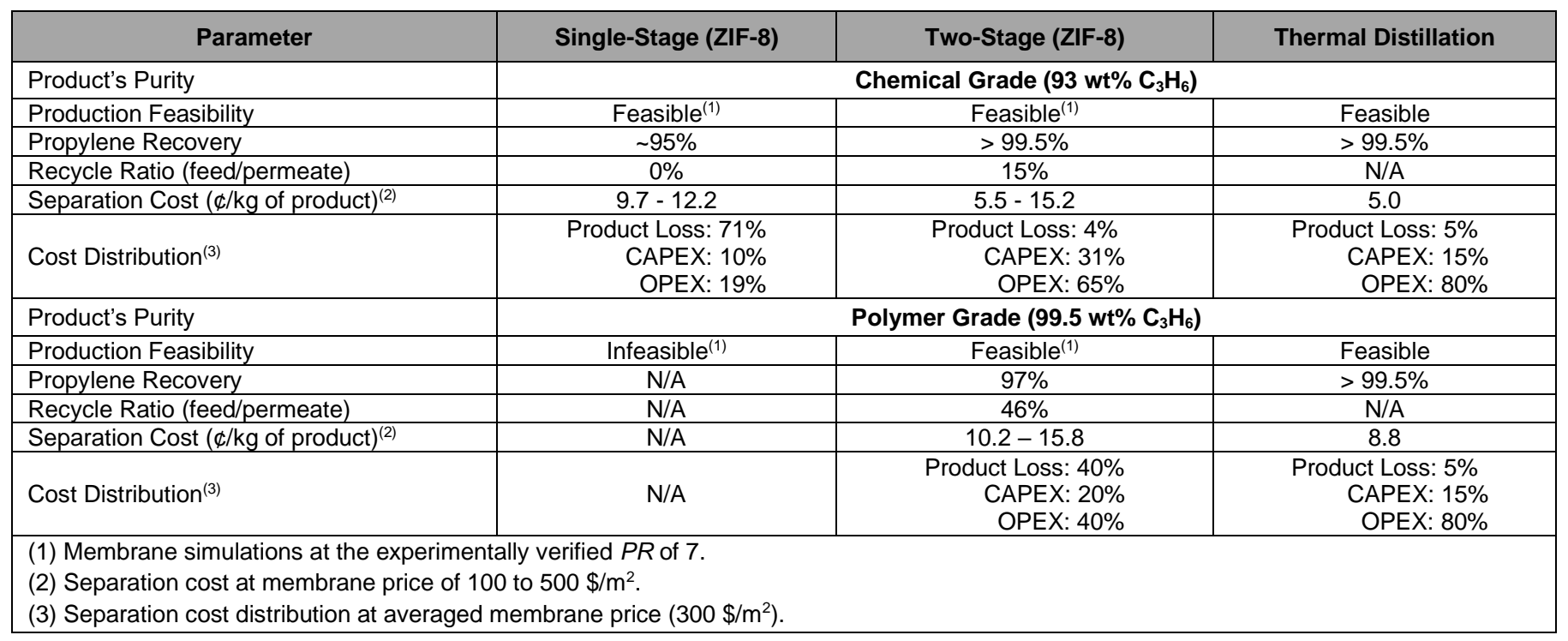

\section{SUMMARY AND RECOMMENDATIONS}

This study investigated the possibility of substituting the energy intensive distillation units by compacted and more energy efficient ZIF-8 membrane units, should the ZIF-8 membrane be available for industrial use.

Considering a typical feed (70 wt\% propylene), the capability of a single-stage process is found limited to the production of chemical grade propylene (recovery $>95 \%$ ). To produce the polymer grade at reasonable recovery, the utilization of a two-stage process is a firm requirement. The latter indicated conclusions are valid even if the selectivity of the ZIF-8 membranes approached that of pure ZIF-8 crystals. The installation of the second membrane stage moderates the low recovery caused by the membrane's imperfection. At the assumed membrane prices of $100-500$ US $\$ / \mathrm{m}^{2}$, the separation cost in a two-stage ZIF-8 membrane unit is found comparable to that of thermal distillation. This implies that the competency of membrane units is not far from that of distillation. In other words, finding an 
industrial spot for the two-stage ZIF-8 membrane systems in the near future could be possible, subject to improvements in multiple aspects.

The currently published separation properties are proven satisfactory to produce both grades of propylene, subject to proper unit design. Thus, future research should grant more focus towards aspects such as thin-film ZIF-8 membranes manufacturability, mechanical/thermal stability, durability, pre-treatment, contaminants tolerance, etc. Furthermore, the advantages (mainly energy saving) associated with the use of ZIF-8 membranes in hybrid processes are to be investigated. All these aspects must be addressed sufficiently before the ZIF-8 membranes can be commercialized, and subsequently be declared as an alternative to the well-established C3 distillation process.

\section{REFERENCES}

[1] K.-R. Lee, S.-T. Hwang, Separation of propylene and propane by polyimide hollow-fiber membrane module, J. Membr. Sci. 73 (1992) 37-45.

[2] M. Das, Membranes for Olefin/Paraffin Separations, Ph.D. dissertation, Georgia Institute of Technology, USA, 2009.

[3] J.S. Plotkin, The Propylene Quandary, American Chemical Society (2016).

https://www.acs.org/content/acs/en/pressroom/cutting-edge-chemistry/the-propylene-quandary.html (accessed November 18, 2018).

[4] A. Alshehri, Membrane Modeling, Simulation and Optimization for Propylene/Propane Separation, Ph.D. dissertation, King Abdullah University of Science and Technology, Saudi Arabia, 2015.

[5] P. Eisele, R. Killpack, Propene, Ullmann's Encyclopedia of Industrial Chemistry, $6^{\text {th }}$ Ed, Wiley. (2001).

[6] H. Zimmermann, R. Walzl, Ethylene, Ullmann's Encyclopedia of Industrial Chemistry, 6 ${ }^{\text {th }}$ Ed, Wiley. (2001)

[7] T. Ren, M. Patel, K. Blok, Olefins from conventional and heavy feedstocks: Energy use in steam cracking and alternative processes, Energy. 31 (2006) 425-451.

[8] Y.-H. Chu, D. Yancey, L. Xu, M. Martinez, M. Brayden, W.J. Koros, Iron-containing carbon molecular sieve membranes for advanced olefin/paraffin separations, J. Membr. Sci. 548 (2018) 609-620.

[9] C. Staudt-Bickel, W.J. Koros, Olefin/paraffin gas separations with 6FDA-based polyimide membranes, J. Membr. Sci. 170 (2000) 205-214.

[10] K. Tanaka, A. Taguchi, J. Hao, H. Kita, K. Okamoto, Permeation and separation properties of polyimide membranes to olefins and paraffins, J. Membr. Sci.121 (1996) 197-207.

[11] M. Das, W.J. Koros, Performance of 6FDA-6FpDA polyimide for propylene/propane separations, J. Membr. Sci. 365 (2010) 399-408.

[12] S. Velioğlu, M.G. Ahunbay, S.B. Tantekin-Ersolmaz, Propylene/propane plasticization in polyimide membranes, J. Membr. Sci. 501 (2016) 179-190.

[13] D. Li, E. Long, P. Mwasame, S. Rajagopal, Membranes for Olefin Separations, Senior Design Project, University of Pennsylvania, 2012.

[14] H.T. Kwon, H.-K. Jeong, Improving propylene/propane separation performance of Zeolitic-Imidazolate framework ZIF-8 Membranes, Chem. Eng. Sci. 124 (2015) 20-26.

[15] Y. Pan, T. Li, G. Lestari, Z. Lai, Effective separation of propylene/propane binary mixtures by ZIF-8 membranes, J. Membr. Sci. 390-391 (2012) 93-98.

[16] M. Kanezashi, W. Shazwani, T. Yoshioka, T. Tsuru, Separation of propylene/propane binary mixtures by bis(triethoxysilyl) methane (BTESM)-derived silica membranes fabricated at different calcination temperatures, J. Membr. Sci. 415-416 (2012) 478-485. 
[17] N. Hara, M. Yoshimune, H. Negishi, K. Haraya, S. Hara, T. Yamaguchi, Diffusive separation of propylene/propane with ZIF-8 membranes, J. Membr. Sci. 450 (2014) 215-223.

[18] Z. Olujic, F. Fakhri, A.D. Rijke, J.D. Graauw, P. Jansens, Internal heat integration - the key to an energyconserving distillation column, J. Chem. Techn. \& Biotechn. 78 (2003) 241-248.

[19] M.L. Tanco, D.P. Tanaka, Recent Advances on Carbon Molecular Sieve Membranes (CMSMs) and Reactors, Processes, 4 (2016) 29.

[20] H. Jarvelin, J.R. Fair, Adsorptive separation of propylene-propane mixtures, Ind. Eng. Chem. Res. 32 (1993) 2201-2207.

[21] A. Chauvel, G. Lefebvre, Synthesis-gas derivatives and major hydrocarbons, 2nd ed., Editions Technips, 1989.

[22] R.B. Eldridge, Olefin/paraffin separation technology: a review, Ind. Eng. Chem. Res. 32 (1993) 2208-2212.

[23] R.L. Burns, W.J. Koros, Defining the challenges for $\mathrm{C}_{3} \mathrm{H}_{6} / \mathrm{C}_{3} \mathrm{H}_{8}$ separation using polymeric membranes, J. Membr. Sci. 211 (2003) 299-309.

[24] I.K. Kookos, Optimal Design of Membrane/Distillation Column Hybrid Processes, Ind. Eng. Chem. Res. 42 (2003) 1731-1738.

[25] K. Okamoto, K. Noborio, J. Hao, K. Tanaka, H. Kita, Permeation and separation properties of polyimide membranes to 1,3-butadiene and n-butane, J. Membr. Sci. 134 (1997) 171-179.

[26] W.J. Koros, Model for sorption of mixed gases in glassy polymers, J. Polym. Sci.: Polym. Phys. Ed., 18 (1980) 981-992.

[27] W.J. Koros, R.T. Chern, V. Stannett, H.B. Hopfenberg, A model for permeation of mixed gases and vapors in glassy polymers, J. Polym. Sci.: Polym. Phys. Ed., 19 (1981) 1513-1530.

[28] C.W. Colling, G.A. Jr. Huff, J.V. Bartels, Processes using solid permselective membranes in multiple groups for simultaneous recovery of specified products from a fluid mixture, U.S. Patent 6,830,691 (2004).

[29] B.D. Freeman, D.F. Sanders, Z.P. Smith, R. Guo, L.M. Robeson, J.E. Mcgrath, D.R. Paul, Energy-efficient polymeric gas separation membranes for a sustainable future: A review, Polymer 54 (2013) 4729-4761.

[30] W.J. Koros, L. Xu, M. Rungta, M.K. Brayden, M.V. Martinez, B.A. Stears, G.A. Barbay, Olefins-selective asymmetric carbon molecular sieve hollow fiber membranes for hybrid membrane-distillation processes for olefin/paraffin separations, J. Membr. Sci.423-424 (2012) 314-323.

[31] M. Matsukata, K.-I. Sawamura, Y. Sekine, E. Kikuchi, Chapter 8 - Review on Prospects for Energy Saving in Distillation Process with Microporous Membranes, Membrane Science and Technology. 14 (2011) 175-193.

[32] J.H. Ryu, H. Lee, Y.J. Kim, Y.S. Kang, H.S. Kim, Facilitated olefin transport by reversible olefin coordination to silver ions in a dry cellulose acetate membrane, Chem. Eur. J. 7 (2001) 1525-1529.

[33] A.S. Kovvali, H. Chen, K.K. Sirkar, Glycerol-based immobilized liquid membranes for olefin-paraffin separation, Ind. Eng. Chem. Res. 41 (2002) 347-356.

[34] H.S. Kim, S.J. Park, D.Q. Nguyen, J.Y. Bae, H.W. Bae, H. Lee, S.D. Lee, D.K. Choi, Multi-functional zwitterionic compounds as new membrane materials for separating olefin paraffin mixtures, Green. Chem. 9 (2007) 599-604.

[35] T.C. Merkel, Z. He, A. Morisato, I. Pinnau, Olefin/paraffin solubility in a solid polymer electrolyte membrane, Chem. Commun., (2003) 1596-1597.

[36] Y.S. Kang, S.W. Kang, J.H. Kim, K. Char, J. Won, Nanocomposite silver polymer electrolytes as facilitated olefin transport membranes, J. Membr. Sci. 285 (2006) 102-107. 
[37] J.Z. Ren, Y.B. Wang, M.C. Deng, Ultrathin solid polymer electrolyte PEl/Pebax2533/AgBF(4) composite membrane for propylene/propane separation, Sep. Purif. Technol. 77 (2011) 46-52.

[38] J. Hayashi, H. Mizuta, M. Yamamoto, K. Kusakabe, S. Morooka, S.H. Suh, Separation of ethane/ethylene and propane/propylene systems with a carbonized BPDA-pp'ODA polyimide membrane, Ind. Eng. Chem. Res. 35 (1996) 4176-4181.

[39] A.B. Fuertes, I. Menendez, Separation of hydrocarbon gas mixtures using phenolic resin-based carbon membranes, Sep. Purif. Technol., 28 (2002) 29-41.

[40] M. Yoshino, S. Nakamura, H. Kita, K. Okamoto, N. Tanihara, Y. Kusuki, Olefin/paraffin separation performance of carbonized membranes derived from an asymmetric hollow fiber membrane of 6FDA/BPDA-DDBT copolyimide, J. Membr. Sci. 215 (2003) 169-183.

[41] Y.M. Lee, H.B. Park, Fabrication and characterization of nanoporous carbon/silica membranes, Adv. Mater. 17 (2005) 477-483.

[42] M.N. Islam, W.L. Zhou, T. Honda, K. Tanaka, H. Kita, K. Okamoto, Preparation and gas separation performance of flexible pyrolytic membranes by low temperature pyrolysis of sulfonated polyimides, J. Membr. Sci. 261 (2005) 1726.

[43] M.L. Chng, T.S. Chung, Y.C. Xiao, M. Toriida, S. Tamai, Enhanced propylene/propane separation by carbonaceous membrane derived from poly (aryl ether ketone)/2,6-bis(4-azidobenzylidene)-4-methyl cyclohexanone interpenetrating network, Carbon 47 (2009) 1857-1866.

[44] I. Pinnau, L.G. Toy, Solid polymer electrolyte composite membranes for olefin/paraffin separation, J. Membr. Sci.184 (2001) 39-48.

[45] P. Bernardo, E. Drioli, G. Golemme, Membrane gas separation: A review/state of the art, Ind. Eng. Chem. Res. 48 (2009) 4638-4663.

[46] J.-I. Hayashi, M. Yamamoto, K. Kusakabe, S. Morooka, Effect of oxidation on gas permeation of carbon molecular sieving membranes based on BPDA-pp‘ODA polyimide, Ind. Eng. Chem. Res. 36 (1997) 2134-2140.

[47] M. Kanezashi, T. Matsutani, H. Nagasawa, T. Tsuru, Fluorine-induced microporous silica membranes: Dramatic improvement in hydrothermal stability and pore size controllability for highly permeable propylene/propane separation, J. Membr. Sci. 549 (2018) 111-119.

[48] M. Kanezashi, S. Miyauchi, H. Nagasawa, T. Yoshioka, T. Tsuru, Gas permeation properties through Al-doped organosilica membranes with controlled network size, J. Membr. Sci. 466 (2014) 246-252.

[49] M. Tsapatsis, X. Ma, P. Kumar, N. Mittal, A. Khlyustova, P. Daoutidis, K.A. Mkhoyan, Zeolitic imidazolate framework membranes made by ligand-induced permselectivation (Supplementary Material), Science, 361 (2018) 1008-1011.

[50] Y. Lin, D. Liu, X. Ma, H. Xi, Gas transport properties and propylene/propane separation characteristics of ZIF-8 membranes, J. Membr. Sci. 451 (2014) 85-93.

[51] D. Fairen-Jimenez, S.A. Moggach, M.T. Wharmby, P.A. Wright, S. Parsons, Düren T., Opening the Gate: Framework Flexibility in ZIF-8 Explored by Experiments and Simulations, J. Am. Chem. Soc. 133 (2011) 8900-8902.

[52] H.T. Kwon, H.-K. Jeong, Highly propylene-selective supported zeolite-imidazolate framework (ZIF-8) membranes synthesized by rapid microwave-assisted seeding and secondary growth, Chem. Commu. 49 (2013) 3854.

[53] Y.-R. Lee, M.-S. Jang, H.-Y. Cho, H.-J. Kwon, S. Kim, W.-S. Ahn, ZIF-8: A comparison of synthesis methods, Chem. Eng. J. 271 (2015) 276-280. 
[54] C. Zhang, R.P. Lively, K. Zhang, J.R. Johnson, O. Karvan, W.J. Koros, Unexpected molecular sieving properties of zeolitic imidazolate framework-8, J. Phys. Chem. Lett. 3 (2012) 2130-2134.

[55] Y. Pan, L. Sheng, C. Wang, F. Yang, L. Xiang, X. Huang, J. Yu, L. Zhang, Y. Li, Enhanced $\mathrm{C}_{3} \mathrm{H}_{6} / \mathrm{C}_{3} \mathrm{H}_{8}$ separation performance on MOF membranes through blocking defects and hindering framework flexibility by silicone rubber coating, Chem. Comm. 53 (2017) 7760-7763.

[56] X. Ma, R.J. Swaidan, Y. Wang, C.-E. Hsiung, Y. Han, I. Pinnau, Highly Compatible Hydroxyl-Functionalized Microporous Polyimide-ZIF-8 Mixed Matrix Membranes for Energy Efficient Propylene/Propane Separation, ACS Applied Nano Materials. 1 (2018) 3541-3547.

[57] A.K. Datta, P.K. Sen, Optimization of membrane unit for removing carbon dioxide from natural gas, J. Membr. Sci. 283 (2006) 291-300.

[58] M. Hoorfar, Y. Alcheikhhamdon, B. Chen, A novel tool for the modeling, simulation and costing of membrane based gas separation processes using Aspen HYSYS: Optimization of the $\mathrm{CO}_{2} / \mathrm{CH}_{4}$ separation process, Computers \& Chem. Eng. 117 (2018) 11-24.

[59] A. Kazemi, A. Mehrabani-Zeinabad, M. Beheshti, Distillation without hot utilities; development of novel distillation configurations for energy and costs saving for separation of propylene/propane mixture, Chemical Engineering and Processing - Process Intensification. 123 (2018) 158-167.

[60] N. Chemmangattuvalappil, S. Chong, Basics of Process Simulation with Aspen HYSYS - Chapter 11, Chemical Engineering Process Simulation. (2017) 233-252.

[61] J. Hao, P. Rice, S. Stern, Upgrading low-quality natural gas with $\mathrm{H}_{2} \mathrm{~S}$ - and $\mathrm{CO}_{2}$-selective polymer membranes: Part I. Process design and economics of membrane stages without recycle streams, J. Membr. Sci. 209 (2002) 177206.

[62] J. Hao, P. Rice, S. Stern, Upgrading low-quality natural gas with $\mathrm{H}_{2} \mathrm{~S}$ - and $\mathrm{CO}_{2}$-selective polymer membranes: Part II. Process design, economics, and sensitivity study of membrane stages with recycle streams, J. Membr. Sci. 320 (2008) 108-122.

[63] M.S. Peters, K.D. Timmerhaus, Plant design and economics for chemical engineers, McGraw-Hill, New York, 1991.

[64] Y. Huang, T.C. Merkel, R.W. Baker, Pressure ratio and its impact on membrane gas separation processes, J. Membr. Sci. 463 (2014) 33-40.

[65] U. Maheshwari, R. Shilawant, D. Biswas, S. Chellappan, International Symposium \& 64th Annual Session of IIChE, in: Optimization of Propylene-Propane Distillation Process Using ASPEN PLUS, Bangalore, 2011. 